\title{
Promotion Incentives and Teacher Effort in China
}

\begin{abstract}
This paper examines the effort incentives of teachers in rural China. China employs a complex system of annual evaluations and promotions for civil servants in which good evaluations, along with a teacher's years of service and education, make teachers eligible to apply for rank promotions. A model of promotions is developed in which agents are both incentivized, and are sorted into ranks by ability. The model's predictions are then tested using panel data on teachers collected as part of the Gansu Survey of Children and Families (GSCF). We find that teachers respond to promotion incentives as predicted by the model: salary differentials are used to motivate teachers to work harder and teachers do work hard for promotions; teachers that are repeatedly passed over for promotions tend to slack off, as do teachers that have been doing well in the past; increased competition in the form of more teachers increases incentives when the probability of promotion is between $1 / 3$ and $2 / 3$; and effort is low when the probability of promotion is close to zero or one.
\end{abstract}

\section{Introduction}

The centrality of teachers to the learning process is well established (Glewwe, 2002). However, in many low income countries, teachers' incentives are weak, as evidenced in part by extremely high absence rates and by low student performance. Most often, teachers are paid based on their experience and education rather than on their performance. This phenomenon has led to increased interest in incentivizing teachers with the hope that it will have a positive effect on teacher effort and on student achievement. As a result, there has recently been a push towards studying and implementing performance pay systems, both in the developed world (particularly in the United States) as well as in low income countries. Incentivizing teachers is generally framed in the context of performance pay (bonuses), and is often based on annual evaluations. However, the use of performance pay for teachers is not widespread, particularly in the developing world. At the moment, promotions remain the primary source of incentives for teachers in many contexts. It is important, therefore, to study the impact of such systems on teachers' effort. 
There has been a debate in the literature on the merits of incentives through performance pay (bonuses) versus promotions. The literature has shown that performance pay systems are susceptible to gaming and influence activities (Figlio \& Kenny, 2006). However, a seminal paper by Baker, Jensen and Murphy argues that, 'promotion-based incentive schemes have many disadvantages and few advantages relative to bonus-based incentive schemes' (Baker, Jensen and Murphy, 1988, p. 600). Specifically, they argue that managers may have an incentive to manipulate the promotion system by accepting bribes. So, perhaps promotions should be used for sorting of employees and bonuses should be used for incentives. However, as Fairburn and Malcolmson (2001) argue, promotions can actually overcome the disadvantages noted by Baker, Jensen and Murphy, as a bonus system is also susceptible to influence activities, but a promotion system can be made incentive compatible. They note that, 'as long as managerial rewards are tied in some way to the short term performance of the section for which the manager is responsible, the manager has an interest in ensuring that the appropriate employees are promoted' (Fairburn and Malcolmson, 2001, p. 46). If this is the case, then perhaps the focus on performance pay for teachers is unwarranted, and implementing an optimal promotion system would elicit more effort from teachers. This paper will use the case of China to study features of its promotion system, and will attempt to glean which features work well, and which ones do not work as well.

China's bureaucratic system is unique for a low-income country, in that civil servants enter the government at an entry-level position and then compete with their colleagues for promotions. This is also the case for teachers in China. Each school has an allocation of ranks set by the district education authority (which come with increasing salary levels) and teachers must compete for positions at higher levels based on their education, experience and annual evaluation scores. Bonuses are not awarded to teachers, and as such, promotions are the main source of incentives. Furthermore, the promotion system for civil servants in China is a very sophisticated one and thus provides an excellent opportunity to study this topic.

This paper will study the effects of this evaluation and promotion system on teacher effort in Gansu province in rural China. In particular, it will focus on the effects of time after promotion for various rank levels, as well as on measures of competition and ability. We will do this by first developing a model based on that of Gibbs (1989), that models promotions as having both a sorting and incentivizing function. We then test the predictions of the model using panel data obtained from the Gansu Survey of Children and Families (GSCF). We measure effort using the teachers' reported annual evaluation scores for the years 2003-2006. We use a teacher fixed effects specification with dummies for the number of years after promotion, and we include various 
measures of competition and ability. We find that the predictions of the model are largely corroborated: promotions are indeed used to motivate effort and that teachers do work hard for promotions; teachers that are repeatedly passed over for promotions tend to slack off, as do teachers that have been doing well in the past; increased competition in the form of more teachers increases incentives when the promotion rate is between $1 / 3$ and $2 / 3$; and effort is low when the probability of promotion is close to zero or one.

The paper is organized as follows. The following section will outline some previous work on this topic, and Section III will detail the theoretical model. Section IV will explain the data as well as the rationale behind the study, and Section $V$ will present the empirical specifications used for the tests, as well as some potential concerns with the estimation strategy. Section VI will present the results of the econometric tests, and Section VII will conclude.

\section{Related Literature}

This section provides the context for this research. It outlines previous research and findings and describes how this paper will build on them. There are three strands of literature related to this study: the literature on motivating and incentivizing teachers, the literature concerning education and in particular teachers in China, and the labour economics literature that studies promotions as incentives through both theoretical models and empirical evidence.

\section{Teacher Incentives}

The studies on teacher incentives carried out thus far focus on performance pay and have investigated the impacts of both individual and group incentive schemes on student outcomes and on teacher attendance. They attempt to glean whether basing pay on performance, or on closer monitoring, or both, leads to increased effort on the part of teachers, as measured by student outcomes. They point to positive gains in both respects, however, they also uncover gaming behaviour in some cases.

Lavy (2002) and Lavy (2003) study a group incentive program and an individual incentive pay program, respectively, in Israel. Lavy documents improved student achievement in both as a result of the schemes. Glewwe et al (2003) undertake a randomized study in Kenya involving group incentives, and find that student test scores do indeed improve, but that teacher effort may suffer in other dimensions, as teachers were found to be 'teaching to the test'. Duflo and Hanna (2005) also undertake a randomized trial by installing tamper-proof cameras in Indian schools, coupled with 
high-powered financial incentives based on reported attendance of teachers. They find that attendance improved significantly, as did student achievement. Muralidharan and Sundararaman (2009) study a randomized trial with both a group and an individual incentive pay scheme based on student test scores in Andhra Pradesh, India. They find that the incentivized schools outperform the control schools, and that the individual incentive treatment group outperformed the group incentive treatment group.

Numerous studies have also been carried out in the US. Figlio and Kenny (2006) consider individual incentives, and report positive effects on student achievement. However, their data is cross-sectional. Other studies in the US have pointed to evidence of gaming, particularly, teaching to the test, providing high calorie lunches on test days, and placing certain students in special education classes to raise average scores (Figlio and Winicki, 2002; Figlio and Getzler, 2002; Jacob and Levitt, 2003). Thus, studying the various responses to incentives is important.

\section{Teachers in China}

A number of papers have used the GSCF data to study various aspects of the education system in China, including education management, financing and decentralization, school attainment, and educational resources (see GSCF website). Park and Hannum (2001) study the effects of educational inputs on student achievement in Gansu province, particularly, teachers as an input. They use teacher rank titles as a proxy for teacher quality, as they are meant to measure several dimensions of teacher ability, performance and effort. They find that teacher quality is extremely important, particularly for language scores of students.

Ding and Lehrer (2001) examine the evaluation and pay system in Jiangsu province in China. They present a model of a performance measure that combines both objective and subjective elements, and test the model empirically. They find that teacher salaries are positively related to both objective and subjective performance measures, that salaries increase with rank, and that teachers that are male, more educated, older, and have more education, tend to be in higher ranks. However, this work does not study the effort incentives from the evaluations and promotions.

\section{Promotions as Incentives}

The theoretical and empirical literature related to this study is concerned with the internal labour market of firms. This literature regards promotions as having two functions: to sort employees by ability, and to provide incentives for effort. The idea of promotions as an incentive 
device is closely linked to the theory of tournaments ${ }^{1}$. Tournament theory states that a firm can motivate employees by having them compete for a reward (a promotion) (Gibbs, 1994). Tournament models of promotion take Lazear and Rosen's (1981) rank-order tournament model as their starting point. Here, two players compete for a promotion (which implies an increase in wages) and only the person with the higher output wins it. In their model, effort is unobservable and output depends on effort and a random component. They show that there exists a wage gap that will induce the first-best level of effort. Other papers that study promotion tournaments include Malcolmson (1984), Rosen (1986), and Baker, Jensen and Murphy (1988).

The literature on sorting of employees into ranks or jobs is based on Sattinger (1975), Rosen (1982) and Waldman (1984), as well as MacLeod and Malcolmson (1988). In these models, a job ladder is generated endogenously within the firm. MacLeod and Malcolmson (1988) present a promotion model in which ability (which varies across employees) and effort are private information. The firm sets up an internal labour market with different ranks and higher wages at higher ranks. There is a distribution of ability types $a$ and effort levels $e$. Disutility of effort is lower with higher ability $(c(e) / a)$. The model predicts that employees will sort into ranks according to ability; the people that get promoted are those for which their ability justifies their effort for working hard and being promoted. People with higher ability work also harder to get the next promotion.

Fairburn and Malcolmson (1994) model a case where the firm would like to sort employees into different jobs. They note that it is generally a manager who reports on employees' performance and recommends bonuses, and that these managers may be susceptible to 'influence activities' on the part of employees that may make the promotions inefficient in the sense that more employees could be promoted than would be optimal. However, if promotions are used in conjunction with bonuses to sort employees into different jobs, then even when influence is possible, effort will be increased $^{2}$. Papers that study promotions as sorting devices highlight either learning or human capital acquisition as the way of adding dynamics to the promotion process (Gibbons and Waldman, 1999).

\footnotetext{
${ }^{1}$ There are two other strands of literature related to incentives. The first is that related to agency models and incentive contracting as developed by Mirrlees (1974, 1976), Holmstrom (1979), Holmstrom (1999) and Shavell (1979) which focus on the tradeoffs between risk and incentives. The efficient contract involves providing the employee with a bonus to elicit optimal effort. The second is the efficiency wage approach in which the firm elicits effort by paying a wage that is above the market-clearing level and threatening to fire the employee if he/she exhibits performance that is too low (Gibbons and Waldman, 1999).

${ }^{2}$ Many other papers study various incentives of managers, including Milgrom (1988), Milgrom and Roberts (1988), and Prendergast and Topel (1996).
} 
Gibbs' (1989) extends the Lazear and Rosen (1981) basic tournament model to multi-person tournaments, and incorporates the use of an internal hierarchy in the firm to sort employees according to ability. The paper shows that in a multi-person tournament with heterogeneous agents competing for a series of promotions, employees with higher ability tend to be promoted, so employees sort into ranks according to ability, and that promotions can provide both efficient sorting and effort incentives. Furthermore, the number of competitors and the distribution of skills amongst employees, as well as the wage differentials at different ranks, all have an important influence on effort incentives. We will return to this model in the theory section. Gibbs' model is expounded in two further papers, Gibbs (1990) which compares tournaments and standards, and Gibbs (1991) which details more carefully the incentive effects for employees with varying ability.

Early empirical studies of tournaments used data from auto racing and chicken farming, rather than compensation and firm level data. Empirical studies of tournaments take the approach of testing tournament theory versus other wage theories such as marginal productivity, to see which one holds for the data (Baker, Gibbs and Holmstrom, 1994b; Medoff and Abraham, 1980; Medoff and Abraham, 1981). The log of the wage is generally used as the outcome variable. For example, Baker, Gibbs and Holmstrom (1993) use personnel data from a large firm in the US with multiple levels in the hierarchy and regress rank titles on wages. They find that the ranks explain $70 \%$ of variation in wages, and that individuals experience larger wage increases with promotions. They use this as evidence that the firm uses promotions as incentives. However, the effect of those incentives on effort is not studied. Much empirical evidence on tournament theory also focuses on CEO pay as a way to test tournament theory as the wage gap at the top level is expected to be large (Bognanno, 2001).

However, these studies do not include a performance measure in their estimations and as a result, they do not get at effort incentives. Furthermore, their studies focus on middle-level managers, generally in the US, in the private sector. Gibbs (1995) uses the same personnel data as Baker et. al. (1993) along with performance ratings, and focuses on middle managers. He finds that both promotions and bonuses are used as incentives in this firm, and that employees that are repeatedly passed over for promotion have greatly reduced incentives. Campbell (2008) is one of few studies that looks at non-financial performance measures. He studies managers of a fast food outlet, and he finds that these non-financial measures do indeed factor into promotion decisions. Furthermore, he provides evidence that promotion incentives affect behaviour; stronger incentives lead to greater improvements in qualitative performance indicators. Kwon (2006) studies effort in human capital accumulation but focuses on women at lower levels, and again in a private-sector 
setting. In this paper, we focus on effort incentives rather than on testing tournaments, and look specifically at effort incentives over time and in response to various measures of competition. Furthermore, our setting is the public sector in a low-income country. We are unaware of any other such studies. The next section will outline the theoretical model that the data will be used to test.

\section{A Model of Promotions as Incentives}

This section will detail a model of promotions as incentives. The following exposition is based primarily on Gibbs (1990) as well as on Gibbs (1989) and partially on Gibbs (1991). Teachers differ in terms of skill/ability, s. Teachers contribute effort to their job (this includes diligence, care etc., not just hours), but effort is costly and gives them disutility $C(e)$ which is increasing in $e$ at an increasing rate so that $C^{\prime}$ and $C^{\prime \prime} \geq 0$. The school would like to both motivate effort and to sort employees by ability. The performance measure is $q=s+e+\eta$ where $q$ can be thought of as teaching output (student learning, growth as individuals, etc.) and $\eta$ is measurement error, which we assume has a symmetric distribution around a single mode of zero ${ }^{3}$.

A teacher's probability of being promoted depends on his/her skill and chosen effort, but the teacher does not know his/her $s$ relative to that of others, nor does he/she know the school's estimate of his/her $s$, so beliefs on $s$ are important. We assume that a teacher's subjective beliefs about $s$ are characterized by a symmetric, unimodal distribution with mean $\bar{s}$. $\bar{s}$ is a function of the teacher's information about performance in previous periods and varies across teachers. Thus, to the teacher, there are two types of luck: the actual value of $s$ relative to $\bar{s}$ (i.e. $s-\bar{s}$ ) and the measurement error $\eta$. Define the combined luck as $\theta=s-\bar{s}+\eta$ so that $q=\bar{s}+e+\theta$ and define $\varepsilon=\bar{s}$ $+\theta^{4}$ so now $q=e+\varepsilon$. Denote the CDF and PDF of $\varepsilon$ as $F(\varepsilon)$ and $f(\varepsilon)$ respectively. Given the previous assumptions, $\theta$ is symmetric and unimodal at $\bar{s}$ if $s$ and $\eta$ are independent.

A teacher's probability of promotion can be written as $p=p(\bar{s}, e, \underline{e})$ where $\underline{e}$ is a vector of other teachers' efforts. Without loss of generality we can assume that the average value of $\bar{s}$ across teachers is zero, and $\bar{s}$ can be interpreted as the teacher's best guess about his/her skill relative to the average teacher in his/her rank, so $E(\varepsilon)=0$. The school offers a benefit/reward from promotion, $\triangle E U$, which is the change in expected lifetime utility gained from winning a promotion relative to not being promoted (this could be in the form $\left(W_{2}-W_{1}\right)$, different wages at different ranks where $W_{2}>$ $W_{1}$ if rank 2 is higher than rank 1 , but could also include non-pecuniary benefits).

\footnotetext{
${ }^{3}$ Since the error that arises from measuring a teacher's performance is the sum of many sources of error, this assumption seems reasonable (Gibbs, 1989).

${ }^{4}$ In this way, skill becomes part of the luck draw.
} 
The teacher chooses effort to maximize the expected reward minus the disutility of effort:

$$
\max _{e}^{\max }\{p(\bar{s}, e, \underline{e}) \Delta E U-C(e)\}
$$

The first order condition sets the marginal cost of effort equal to the gain in utility, times the marginal effect of effort on the probability of promotion:

$$
C^{\prime}\left(e^{*}\right)=\frac{\partial p(\bar{s}, e, \underline{e})}{\partial e} \Delta E U
$$

Gibbs terms $\frac{\partial p}{\partial e}$ the marginal probability of effort (MPE). As (2) shows, incentives depend on two things: $\triangle E U$ and $\frac{\partial p}{\partial e}$, the sensitivity of the probability of promotion to changes in effort. The larger the prize $(\triangle E U)$ the greater the incentives. The second order condition is satisfied as long as the probability function does not exhibit too large increasing returns to effort:

$$
\frac{\partial^{2} p}{\partial e^{2}} \Delta E U-C^{\prime \prime}\left(e^{*}\right) \leq 0
$$

In order to study $\frac{\partial p}{\partial e}$, the structure of the promotion contest must be specified. If $n$ teachers are competing for a fixed number, $k$, promotion slots, then this is a tournament structure. The probability of promotion (which is the same as the promotion rate here) is $p=k / n$. Equilibrium effort $e^{*}$ depends on the actions of other teachers. To win a promotion, the teacher must place $k^{\text {th }}$ or higher, so he/she must beat at least $n-k$ co-workers in pair-wise comparisons of output.

The probability that teacher $i$ beats teacher $g$ is $p\left(q_{i}>q_{g}\right)=p\left(e_{i}+\varepsilon_{i}>e_{g}+\varepsilon_{g}\right)=p\left(\varepsilon_{g}>e_{i}-e_{g}+\right.$ $\left.\varepsilon_{i}\right)=F\left(e_{i}-e_{g}+\varepsilon_{i}\right)$. Since no teacher knows his/her skill relative to that of other teachers, a symmetric Nash Equilibrium (NE) is appropriate and optimal effort for all teachers is $e^{*}$. The probability that teacher $i$ beats any other teacher is $F\left(e_{i}-e^{*}+\varepsilon_{i}\right)$ and the probability that teacher $i$ loses to any opponent is $1-F\left(e_{i}-e^{*}+\varepsilon_{i}\right)$. To finish $j^{\text {th }}$ from the top out of $n$ teachers, one must beat $n-j$ teachers and lose to $j-1$ teachers. The probability of doing so for any given partition of competitors, conditional on i's luck $\varepsilon_{i}$ is:

$$
\operatorname{pr}\left(\text { place } j^{\text {th }} \text { out of } n \mid \varepsilon_{i}\right)=\left(\begin{array}{l}
n-1 \\
n-j
\end{array}\right) F\left(e_{i}-e^{*}+\varepsilon_{i}\right)^{n-j} 1-F\left(e_{i}-e^{*}+\varepsilon_{i}\right)^{j-1} \text {. }
$$

The probability of promotion conditional on $\varepsilon_{i}$ is the sum of the conditional probabilities of placing first through $k^{\text {th }}$. Integrating out $\varepsilon_{i}$ gives the unconditional probability of promotion: 


$$
p\left(\bar{s}, e, \underline{e}^{*}\right)=\sum_{j=l}^{k}\left(\begin{array}{c}
n-1 \\
n-j
\end{array}\right) \int F\left(e-e^{*}+\varepsilon\right)^{n-j}\left(1-F\left(e-e^{*}+\varepsilon\right)\right)^{j-1} f(\varepsilon) d \varepsilon
$$

where the subscript $i$ has been dropped for notational convenience. If $p=0$ or 1 ( $k=0$ or $n$ ) so that either everyone or no-one is promoted, then $p(\bar{s}, e, \underline{e})$ is constant and the MPE and incentives are zero. Nobody has an incentive to work.

To solve for the MPE we need to differentiate with respect to $e$ and substitute in the symmetric NE condition $e_{i}=e^{*}$. After rearranging, we have:

$$
\frac{\partial p}{\partial e}=(n-k)\left(\begin{array}{c}
n-1 \\
n-k
\end{array}\right) \int F(\varepsilon)^{n-k-1}(1-F(\varepsilon))^{k-1} f(\varepsilon)^{2} d \varepsilon
$$

Now we can analyze $\frac{\partial p}{\partial e}$. A teacher is trying to beat the $n-k-1^{\text {st }}$ order statistic (the random variable that is the $n-k-1^{\text {st }}$ score (from the bottom) among competitors). Denote this order statistic $\tau$. Subtracting off optimal effort of competitors gives the luck $\varepsilon$ required to win, $\lambda=\tau-e^{*}$. With a symmetric NE effort terms cancel out and $\lambda$ is also an order statistic, the $n-k-1^{\text {st }}$ (from the bottom) among the $n$ - 1 competitors. Let this random variable have $\operatorname{CDF} G(\lambda)$ and PDF $g(\lambda)$. For any given luck $\varepsilon$, the probability of promotion equals:

$$
\operatorname{pr}(\operatorname{promoted} \mid \varepsilon)=p(e+\varepsilon>\tau \mid \varepsilon)=p\left(e+\varepsilon>e^{*}+\lambda \mid \varepsilon\right)=G\left(e-e^{*}+\varepsilon\right) .
$$

Integrating over the luck distribution provides the unconditional probability of promotion, $p=\int G\left(e-e^{*}+\varepsilon\right) f(\varepsilon) d \varepsilon(4)$ where the integrand except for $f(\varepsilon)$ is an order statistic density. This shows that the MPE is independent of equilibrium effort; it depends only on $k$ and $n$. We can simplify (4) by making use of change of variables $\psi \equiv F(\varepsilon)$. Since $f d \varepsilon=d F=d \psi$, and $\varepsilon=F^{1}(\psi)$ we can write:

$$
\frac{\partial p}{\partial e}=\int(n-k)\left(\begin{array}{c}
n-1 \\
n-k
\end{array}\right) \psi^{n-k-1}(1-\psi)^{k-1} f\left(F^{-1}(\psi)\right) d \psi
$$

This integrand, except for $f\left(F^{-1}(\psi)\right)$, has the form of a Beta density function $\beta(k, n-k)^{5}$. Thus, $\psi$ has the effect of a Beta-distributed random variable and

$$
\frac{\partial p}{\partial e}=E_{\psi} f\left(F^{-1}(\psi)\right)
$$

\footnotetext{
${ }^{5}$ Order statistics of the uniform distribution on the unit interval have marginal distributions of the Beta distribution family.
} 
When $f(\varepsilon)$ is symmetric and unimodal at 0 then $f\left(F^{-1}(\psi)\right)$ is symmetric over $[0,1]$, unimodal at $1 / 2$ and $f\left(F^{-1}(1 / 2)\right)=f(0)$.

Gibbs then provides a number of propositions and predictions using properties of Beta densities, some of which we summarize here, providing the intuition. The most relevant property of Beta densities is as follows: $\beta(k, n-k)$ is symmetric about one half for $k \geq 1$ if and only if $k=1 / 2 n$ (when half of the teachers are promoted). $\beta(k, n-k)$ is skewed to the right if $k>1 / 2 n$, is skewed to the left if $k<1 / 2 n$, and becomes increasingly skewed as $k / n$ deviates from $1 / 2$ in either direction. The intuition is that when more than half are promoted, the distribution gets skewed to the right. Higher values of luck are more likely so you do not need to work as hard to get a promotion (you are likely to just get lucky) so MPE is lower. When less than half are promoted, the distribution gets skewed to the left. Lower values of luck are more likely so your effort has less bearing on the probability of promotion (you are likely to just be unlucky) so MPE is lower here too. This will be useful for the results below. Figure 3.1 below illustrates. Panel $A$ is for $p=k / n=1 / 2$, Panel $B$ is $p>$ $1 / 2$ and Panel $\mathrm{C}$ is $\mathrm{p}<1 / 2$.

\section{Figure 3.1}

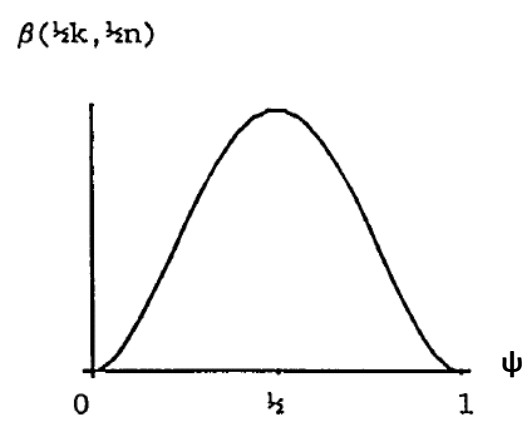

Panel A: $p=1 / 2$

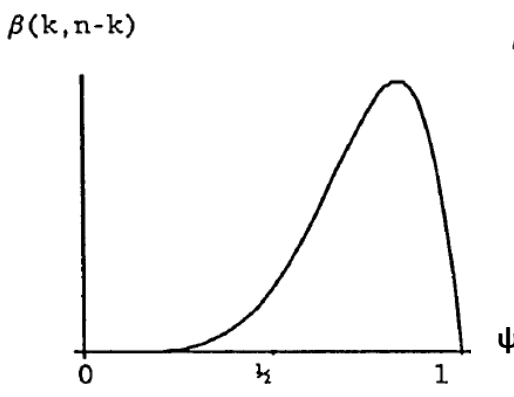

Panel B: $p>1 / 2$

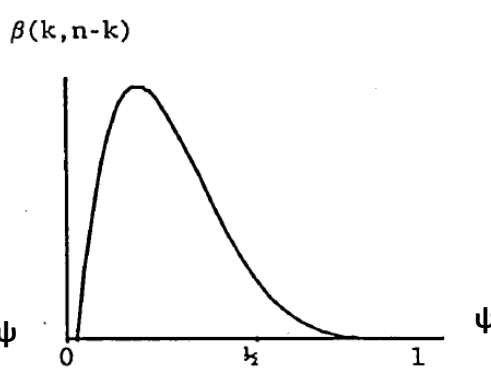

Panel C: $p<1 / 2$

We can see from (5) that because $f(0)=\max (f)$, the marginal probability always has an upper bound that is determined by the distribution of the measurement error $(\varepsilon)$. If $\varepsilon \sim N\left(0, \sigma^{2}\right)$, then $\partial \mathrm{p} / \partial \mathrm{e} \leq\left(2 \pi \sigma^{2}\right)^{-1 / 2}$. As $\sigma^{2}$ gets larger, the upper bound of the MPE decreases. The more noise, the less impact effort has on the probability of being promoted (the density gets flatter so extreme values of good/bad luck are more likely). In the standard two-person tournament (Lazear and Rosen, 1981) increasing noise leads to lower incentives. However, here in the multi-person tournament, incentives are only lowered if $p=1 / 2$. If $p \neq 1 / 2$ then increasing noise may increase incentives by increasing $\partial \mathrm{p} / \partial \mathrm{e}$ depending on the combination of $k$ and $n$ (it may not get flatter). The further $p$ diverges from $1 / 2$, the more extreme values of luck become important as it takes more good or bad 
luck to win or lose. In these cases, increasing the variance of $\varepsilon$ makes winning or losing based on luck more likely so that marginal effort has more effect on the probability of winning.

Another proposition states that if less than half are promoted $(p<1 / 2)$ and if another person is added to the contest ( $n+1$ contestants instead of $n$ ) leaving $\mathrm{k}$ fixed, then effort is less likely to affect your chances of promotion ( $\partial \mathrm{p} / \partial \mathrm{e}$ will be lower) since $p$ will be even further from $1 / 2$ (bad luck will be even more likely). If exactly half are promoted $(p=1 / 2)$ then adding another person leaves effort just as likely to affect your chances of promotion. If more than half get promoted $(p>1 / 2)$ then adding another person means effort is more likely to affect your chances of promotion. Intuitively, as promotion becomes more or less likely ( $p$ approaches 0 or 1 ), more extreme good or bad luck is needed to win or lose the promotion.

An important result is Gibbs' proposition 5: When $f$ is symmetric and unimodal, adding one more winner ( $k+1$ instead of $k$ winners) while keeping the number of contestants, $n$, the same, increases the MPE for $k<1 / 2(n-1)$, keeps the MPE the same for $k=1 / 2(n-1)$, and decreases it for $k>1 / 2(n-1)$, a special case of which is $k=1 / 2 n$ or $p=1 / 2$. If less than half of people get promoted, then adding another winner will increase the effect of effort on your probability of promotion as bad luck is more likely but less so now ( $p$ will be closer to $1 / 2$ ), and the reverse is true for more than half being promoted ( $p$ will be further from $1 / 2$ ). In sum then, holding the prize fixed, incentives rise as the probability of promotion, $p$, rises from 0 to $1 / 2$, incentives peak at $p=1 / 2$, and incentives decrease as $p$ rises from $1 / 2$ to 1 . The model predicts an inverted $U$-shaped relationship between incentives and probability of promotion. Intuitively, if the probability of promotion is exactly half, a teacher is on the margin of being promoted versus not being promoted. It is in this case that effort is most likely to affect the probability of promotion, and incentives are sharpest. Thus, any change in $k$ or $n$ that brings $p$ closer to $1 / 2$ causes incentives to increase. In addition, the effect on incentives is symmetric with respect to $|p-1 / 2|$, the absolute difference of the promotion rate to $1 / 2$. Thus if $p$ is very high or very low we can expect very low effort.

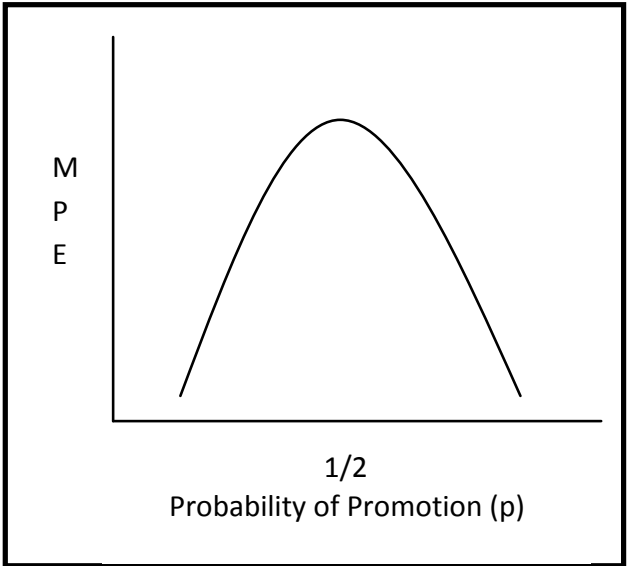

Returning to the effects of the number of competitors, we obtain another prediction. Increasing the number of contestants, $n$, keeping the probability of promotion $k / n$ fixed, raises the MPE if $p=1 / 2$ (the graph gets taller), and generally does so for middle values of $p$ as well (between $1 / 3$ and $2 / 3$ ). For values of $p$ closer to 0 or 1 , increasing $n$ lowers the MPE. This is more likely to hold if $f$ has greater variance or if the contest size is smaller. The greater the number of contestants, the 
smaller the variance in the order statistic that must be beaten to win a promotion. For cases where $p$ is further from $1 / 2$, smaller amounts of luck are more likely to affect who wins and since these are the more likely values of $\varepsilon$ effort has a larger effect on the probability of promotion.

Another prediction of the model is that there is a positive relationship between salary differentials between levels and $|p-1 / 2|$. The difference in salary will be higher for promotion rates closer to zero or one. We can test for this here. For example, promotion rates to Primary high level and Middle high level (the highest levels that can be attained) are quite small so we would expect the salary differential at these levels to be large. Finally, for promotion rates closer to $1 / 2$, larger groups will tend to have smaller rewards. After achieving the final promotion, we can expect effort to cease - since there are no more promotions, there is no incentive for effort.

Thus far, we have assumed homogeneity in beliefs about skills. This framework can be extended by introducing heterogeneity in beliefs about skills. We will consider four ways of doing this. First, consider a case where a teacher believes that his/her probability of promotion differs from $1 / 2$ based on their beliefs about their skill relative to others. If a teacher believes they are far ahead or far behind the $1-p^{\text {th }}$ ability percentile of their peers, their incentives are lower than a teacher that believes he/she is at the margin. This is because those far ahead do not need to put in as much effort to achieve the same objective, and those that believe they are far behind may believe that their effort will not affect their chances of promotion. So for those that believe that they are of very high or low ability, effort may be lower. Another extension is promotions over multiple periods. Often, as is the case here, there are several years between promotions, and promotions can occur at a number of these years. The more a teacher is passed over for promotion, the more heterogeneity in skill beliefs increases. A teacher that has not been promoted updates his/her beliefs on skill (downwards) relative to others in that rank, and also tends to be older and thus enjoy additional earnings from promotion for fewer periods. These teachers would be expected to have lower incentives the longer they stay in a rank.

Third, there are generally multiple promotions in a promotion hierarchy, and future promotions also provide an incentive for effort for lower rank levels as well. Workers at later stages of their career also have better knowledge about their talents and this means that promotions would tend to be spaced further apart later on in a teacher's career. Finally, if promotion is based on previous performance as well (in our case the requirement is to achieve one 'excellent' or two 'good' evaluations ${ }^{6}$ to be eligible to apply for a rank promotion), this would also provide the teacher with information about his/her relative skill and this dampens incentives. A teacher that has been doing

\footnotetext{
${ }^{6}$ The evaluations are on a four point scale: $1=$ fail, $2=$ pass, $3=$ good, $4=$ excellent.
} 
well would tend to slack off. For a worker that has been promoted, he/she knows that his/her skill level is higher than those that were not promoted. However, this is true for all those that were promoted so the teacher does not know his/her skill relative to the new cohort of teachers at this higher rank. In this way, sorting of teachers by ability is achieved and incentives for effort are maintained, even after promotion (Gibbs, 1991).

We expect, then, that effort incentives depend on timing. In the period leading up to the time of promotions, it is unclear as to whether teachers would have an incentive to increase or to reduce effort. It may depend on the teachers' beliefs as to whether earlier or more recent evaluations feature more or equally in the promotion decision. This may also vary by school and depend on the principal's preferences. It is possible that during this period, all teachers would have similar incentives for effort, but later on, once some evaluation scores have been accumulated, there may be more dispersion in effort as teachers are then aware of what they need in order to secure a promotion. During the key promotion period, we would expect effort to be high if promotions are indeed a source of incentives. After this key promotion period, we would expect effort levels to drop. This could be because of the reasons discussed above, that a teacher would update his/her beliefs on ability relative to others, or it could be because a teacher believes that principals just do not promote after a certain amount of time has passed, or because a teacher just does not want to apply for a promotion.

Since beliefs about skill are very important to how a teacher may behave, controlling the information available to a teacher about his/her performance relative to others can be a powerful tool. The objective for the school is to have a teacher believe that he/she is as close to the margin of promotion as possible. This means that the school has an incentive to have very good teachers believe that they are closer to average so that they continue to exert effort, and to have teachers that are falling behind also believe the same so that they do not completely give up. Gibbs notes that this is a possible reason for which we often observe evaluation scores that do not vary very much. Furthermore, since incentives drop off more quickly for those falling behind than they do for those far ahead, the distribution of evaluation scores tends to be skewed towards more positive evaluations (Gibbs, 1991). The presence of such skewing of evaluation scores would make it more difficult to find empirically that promotions increase incentives for effort.

To summarize, the model predicts the following:

1. The larger the expected prize (wage differential), the higher will be effort; 
2. If the probability of promotion, $p$, is exactly $1 / 2$, then increasing the 'noisiness' of the performance measure will lower incentives by lowering the MPE. If $p \neq 1 / 2$ then increasing the noisiness of the performance measure may increase incentives;

3. If $p<1 / 2$ then increasing the size of the pool of competitors will decrease the MPE and incentives will be lower. Incentives remain unchanged if $p=1 / 2$ and they increase for $p>1 / 2$;

4. Incentives are sharpest for those that believe they are just on the margin of being promoted, vs. not being promoted. Those farther away from the margin have lower incentives, and incentives drop off more quickly for those lagging behind than those farther ahead;

5. Incentives are ambiguous for the time period before the key promotion period, are high during the key promotion period, and are lower for those that have been passed over for promotion;

6. Promotions tend to be spaced further apart later on in a teacher's career;

7. Teachers will update their beliefs about their skill relative to others based on previous performance measures. This may reduce incentives;

8. For values of $p$ between $1 / 3$ and $2 / 3$, increasing the number of contestants while leaving $k / n$ fixed increases incentives, and for values of $p$ closer to zero or one, it decreases incentives;

9. Differences in salary will be higher for promotion rates closer to zero or one; and,

10. After the highest promotion, effort will cease.

In the next two sections, we will describe the data used and empiricize this model.

\section{Data}

This section will briefly describe the data used in this paper and will provide some descriptive statistics. Gansu province is located in a topographically diverse area of North West China, and is one of the country's poorest provinces. As of the year 2000 national census, Gansu province had a population of 25.6 million people, $76 \%$ of which live in rural areas. Educational attainment is relatively low compared to the rest of China. By 2000, less than $40 \%$ of the population had completed primary school, and less than $25 \%$ had completed middle school. School conditions and quality vary across the province, however, most principals report that the majority of the teachers in their school have the required qualifications (GSCF website).

The Gansu Survey of Children and Families (GSCF) is a longitudinal study focussing on children and education in Gansu province in rural China. It is the most comprehensive survey on education in rural China, and as such, much information is available that would not be in most 
surveys. In conjunction with the main child questionnaire, a detailed school survey was carried out in each of three waves $(2000,2004$ and 2007) that included interviews of the principal at each school that the children attended, the child's homeroom teacher, as well as interviews of (in most cases) all the teachers at the school.

In China, teachers in primary schools can be assigned to four different ranks: Intern, Primary level 2, Primary level 1 and Primary high level. In middle school, teachers also have four ranks: Middle level 3 (like Intern), Middle level 2, Middle level 1 and Middle high level. Each rank corresponds to a progressively higher salary, and teachers compete for a limited number of slots for promotions. There are specific rules on the years of service required before a teacher can apply for promotion to the next rank level. All teachers begin as interns in their first year, regardless of educational background, and can apply immediately for Primary level 2 or Middle level 2 in the second year. Teachers that graduated from a secondary teacher training school can apply for Primary level 1 or Middle level 1 after 7 years, and for Primary or Middle high level after 15 years. Those graduating from a normal college can apply for Primary level 1 or Middle level 1 after 3 years and Primary or Middle high level after 7 years. Those graduating from universities can apply for Primary or Middle level 1 after one year and for Primary or Middle high level after 5 years (Park and Hannum, 2001). Promotions are based on meeting some minimum requirements, for example, having two 'good' evaluation scores or one 'excellent' evaluation score ${ }^{7}$, having to wait the appropriate number of years before applying to the next rank, and the number of positions available at each rank at each school according to the quotas set by the district.

We use the third round of data that was collected in 2007, from which a panel was constructed for each teacher for the years 2003-2006. The data set was constructed in this way because it was in the third round that data was collected on evaluation scores of all the teachers from 2003-2006. In 2007, individual and household questionnaires, as well as achievement tests, were administered to 1500 children aged ten to fifteen in 20 counties in Gansu province. 250 schools were also surveyed, that included interviews of almost 2500 teachers. The average sampling rate of teachers in the schools is $85 \%$ and only $23 \%$ of the schools have a sampling rate lower than $25 \%$. We only use schools for which the sampling rate is greater than $25 \%^{8}$.

Table 1 provides some basic data on the teachers in our sample. We have data on 2350 teachers, $40 \%$ of whom are female. The data is broken down by current rank of the teacher. We see that in accordance with the findings of Ding and Lehrer for Jiangsu province, teachers in higher ranks

\footnotetext{
${ }^{7}$ Evaluations are conducted on a four point scale: excellent, good, pass, and fail.

${ }^{8}$ We lose about 200 teacher observations. The regressions were also run using only schools with a sampling rate of $50 \%$ or higher, but the results remained unchanged.
} 
tend to be male (the proportion increases sharply over ranks), tend to be older and have more teaching experience, and tend to have higher levels of education. In terms of measures of 'ability', the teachers in higher ranks tend to have performed slightly better on their teaching tests (education, psychology and language tests, which are taken at the beginning of their teaching career), and tend to have received more teaching awards over the course of their career. A higher proportion of higher rank teachers have also published papers on teaching methods in teaching journals. Some of these differences may just be related to the greater number of years of experience. Looking at time use, it seems teachers at lower levels are spending more hours per week on grading, lesson plans, and with students. Again this could be a learning effect; teachers that are in higher ranks have been teaching for longer and thus may need to spend less time on such tasks. They also teach slightly fewer classes. Interestingly, there is quite a sharp decline in the Middle high rank, with these teachers putting in the least amount of time on various tasks. So it seems that there is a correlation between rank and teacher ability; better teachers tend to get promoted, but the effect on effort remains to be seen, thus providing scope to study teacher effort over time.

Table 2 provides a breakdown of evaluation scores by rank of the teacher for the years 20032006. We have four years of data on many teachers, and the total number of teacher-year observations is 7,894 . Not many teachers fail, and the majority of the evaluation scores are a score of 'pass'. There also appears to be a curve; the proportions of teachers receiving each type of evaluation score remain quite similar across ranks. Thus, where a teacher falls in the distribution may be of particular importance.

Figure 1 and Table A1 (in the appendix) look at the number of years until promotion for each of the rank levels. Figure 1 is a set of Kaplan-Meier survival functions for how long a teacher 'survives' at each rank level. Each panel is for the number of years from Primary level 2 until promotion to Primary level 1, Primary level 1 until promotion to Primary high level etc. Most people that get promoted from Primary level 2 to Primary level 1 do so around 4-5 years after having been in Primary 2 rank. We see that practically everyone is promoted at some point, and that the maximum number of years at this level until promotion is 24 years in the sample. For Primary level 1 to Primary high level, the distribution in terms of number of years until promotion is far more spread out. There seems to be a steady stream of promotions, but most people get promoted to Primary high level between 5 and 11 years after promotion to Primary 1 . Just under $1 / 3$ of Primary 1 teachers never get promoted to Primary high. At Middle level 3 rank, every teacher is promoted within 9 years, but the majority of promotions appear to be between 2 and 5 years. At this level, 
promotion is nearly automatic. The promotions from Middle 2 to Middle 1 look similar to those of Primary 1 to Primary high. They are more spread out, but the majority occur between 5 and 10 years. Approximately $25 \%$ of those at Middle level 2 are not (or have not yet been) promoted to Middle level 1. Very few people are promoted from Middle 1 to Middle high level. In this sample, less than $25 \%$ have been promoted to Middle high level. The promotions take considerably longer; anywhere above nine years. Once the teachers reach this level though, as Table 1 demonstrated, there may either be a decline in effort, or a learning effect. Because of the differences in the promotion rates and timing across different ranks, this provides a good opportunity to study differences in effort due to different promotion rates, as well as to study how effort evolves over time.

In the next section, we will detail the empirical specification used to test the model of promotions as incentives, using the GSCF data.

\section{Empirical Specification}

The model specified above leads to a number of testable implications. This section will outline how we will test those predictions and will discuss some potential shortfalls of the estimation strategy. The predictions will be tested in three steps: first, a wage regression will be used to test whether promotions are used as an incentive device. Second, we will study effort over time, and in response to measures of competition. Finally, we will look at the determinants of promotion to see whether evaluations matter for promotion to gauge whether promotions provide effort incentives.

We begin by determining whether or not promotions are used as incentives in this data. We do this following the approach of most other studies that have tested promotions as incentives, using the log of the wage as the outcome. We estimate a cross-sectional Mincer-type wage regression as follows:

$$
\log w_{i}=\alpha+\beta R_{i}+\delta e_{i}+\gamma e_{i}^{2}+\mu E_{i}+\epsilon_{i}
$$

where $w$ is the wage of teacher $i$ from 2007, $\alpha$ is the constant, $R$ is a set of dummies for each of the rank-levels, $e$ is experience and $e^{2}$ is experience squared, $E$ is a set of dummies for the highest level of education that the teacher had achieved in 2007 (primary school, middle school, high school, vocational middle school, vocational college, four year degree and graduate school). If the coefficients on the rank dummies are positive and significant (controlling for education and 
experience), then promotions serve as an incentive device; the ranks explain variation in salary 9 . We can also use this to investigate prediction 9; to see if there may be sharper incentives with certain promotions, i.e. if there are larger salary increases. We expect the coefficients on the rank dummies to be positive and significant, and for the increases in wages to be sharpest for the highest promotion rates (Primary 2 to Primary 1 , Middle 3 to Middle 2) and the lowest promotion rate (Middle 1 to Middle high).

We then examine how the system of evaluations and promotions affects teacher effort, specifically, we look at how effort changes over time depending on the number of years into a rank (prediction 5). We estimate a teacher fixed-effects regression of the teachers' evaluation scores on dummies for the number of years into the rank. The basic estimating equation is:

$$
e_{i t}=\delta X_{i t}+\beta D_{i t}+\omega_{i}+\varepsilon_{i t}
$$

where $e_{i t}$ is the evaluation score of teacher $i$ in time $t$ and proxies for effort, $X_{i t}$ are time-varying teacher characteristics, $D_{i t}$ is a set of dummies for the number of years into a rank, $\omega_{i}$ is the teacher fixed effect, and $\varepsilon_{i t}$ is the time-varying error component ${ }^{10}$. This measures within-teacher variation over time, and identification is from teachers that change from one category to another. Seven sets of regressions are run separately, one for each rank (Primary level 2, Primary level 1, Primary high level, Middle level 3, Middle level 2, Middle level 1 and Middle high level). With Primary high level and Middle high level we would be able to test prediction 10. We have a panel of four years of data for each teacher (2003-2006). The dummies are specified for each of the four years in the panel, for example, a dummy would be one if for primary 2, 2003 was two years after attaining that rank. The next dummy would be one if for primary 2, 2004 was two years after attaining that rank, and so on for each of the possible number of years after promotion, and for each level (the first year after promotion is the omitted category). The coefficients on the dummies will tell us whether effort is higher or lower in year $\mathrm{x}$ after promotion relative to the first year after promotion. This would test predictions 4 and 5; that incentives are sharpest when $p$ is closest to $1 / 2$ (since we know when majority of people become eligible for promotion, we know what $p$ is likely to be over time) and that teachers that are repeatedly passed over for promotions have lower incentives. We expect that during the key promotion period, effort will be higher, and that it will drop the more time teachers spend in a rank, so coefficients on the dummies will become negative and progressively lower.

\footnotetext{
${ }^{9}$ We also estimate a version with ability variables included, and the results were the same so are not reported. ${ }^{10}$ This specification assumes that the teacher fixed effect is correlated with the included regressors, but gets swept away. It also assumes that the dummies are exogenous; we will return to this later.
} 
We then look at other implications of the model, by successively adding measures of 'competition' as well as proxies for ability.

The specification with all of the relevant variables is:

$$
e_{i t}=\delta X_{i t}+\beta D_{i t}+\gamma C_{i t-1}+\delta A_{i t-1}+\omega_{i}+\varepsilon_{i t}
$$

where $C_{i t-1}$ is one or a set of competition variables at time $t-1$, and $A_{i t}$ is the set of measures proxying for ability, or is an ability index, relative to other teachers in that rank at time $t-1$.

The following measures of competition are used:

1. Dummies for whether teacher $i$ received an 'excellent' or a 'good' evaluation score on the previous year's evaluation. This should indicate how teachers behave based on their past performance, and on the information that they receive about it. Do teachers that have been doing well in previous years slack off? A negative coefficient on the dummy for an excellent evaluation would demonstrate this effect. (Prediction 7)

2. The average score of the evaluations of all other teachers in the same rank and same school in the year before. This is meant to capture the way in which a teacher responds to other teachers' performance, or measures of peers effort/ability. (Prediction 7)

3. The proportion of teachers in the same rank in the same school in the year before. This will provide insight as to how effort changes with the number of competitors $(n)$. Note that this is identified by variation over time for the same individual. Here we expect a positive coefficient for promotions where the probability of promotions is between $1 / 3$ and $2 / 3$, i.e. in the key promotion period of Primary 2 to Primary 1, Primary 1 to Primary high, and Middle 2 to Middle 1. (Prediction 8)

Proxies for ability/skill are also included in some specifications. Before teachers apply for a posting, they must take three tests: an education test, a psychology test, and a language test. Scores on these tests are included by first standardizing the scores by the year in which they were taken, and then for each year of the data (2003-2006) the following measure is calculated: [S ave(S)]/ave(S) where $S$ is the standardized score on the tests for a teacher, and ave(S) is the average of the scores of the teachers in the same rank in the same school in the year before ${ }^{11}$. Thus, these measures compare how the teacher scored relative to others in his/her rank and school in the previous year, which is the relevant group that he/she is competing against for promotions. Another measure of ability is the level of education the teacher had when he/she began teaching. Education

\footnotetext{
${ }^{11}$ If in one of these years the teacher was in a lower rank, those are not used (only the current rank is relevant).
} 
is defined in years of education and is relative to other teachers in the same rank and school in the year before (as with the tests above). Finally, we attempted to create an 'ability' index using the three test scores and the number of years of education using Principal Components Analysis (PCA $)^{12}$. The ability index is included by first splitting the index into quintiles and then by including dummies for all but the middle (third) quintile. These dummies are identified off teachers changing from one quintile to another, and they capture a change in the quality of the competition (as this is relative to other teachers). In regressions that include the ability proxies or the index quintile dummies, another variable is also included that controls for the year in which these tests were taken relative to other teachers in the same rank in the same school in the year before. This will account for the fact that the tests would have been different if taken many years ago. The ability measures are meant to capture the effect of beliefs about a teacher's ability relative to those he/she is competing against (prediction 7) and to control for relative ability. ${ }^{13}$ Negative coefficients on the ability variables, similar to finding negative coefficients on the evaluation scores of peers, would mean that teachers revise downwards their beliefs on their ability relative to others, and as a result, put in less effort.

There are some potential problems with our estimation strategy. First, we do not include many teachers' personal characteristics. Those that are time-invariant are swept away by the teacher fixed effect. However, if there are time-varying unobservables that are correlated with variables that are included in the model, then coefficient estimates would be biased. For example, if it were the case that teachers that become wealthier tend to get promoted faster, then coefficient estimates would be biased upwards. However, we do not expect teachers' personal characteristics to vary systematically, and thus their omission should not present a problem. Second, including past evaluations in the regression could cause serial correlation. This is the reason for using the average score of all other teachers as an alternative way to test prediction 7.

Third, there is a selection problem, in that since we are looking at the number of years after a promotion but we only have data for 2003-2006, this means that we have information on people in the sample for different periods of time after promotion. For some we observe the first few years after promotion, for some we observe the next few years, and for some we only observe from

\footnotetext{
${ }^{12}$ Another index was also constructed that standardized each of the variables and then summed them. This did not affect the results.

${ }^{13}$ Other measures of competition were also attempted, including a variable measuring a teacher's rank in the evaluation compared with teachers in the same rank in the same school in the previous year (defined in the same way as the test scores). This measure was also split into dummies for the teacher with the highest ranking and the teacher with the lowest ranking in that rank and school in the year before. A number of interaction effects were also attempted including interacting the proportion of teachers in a rank with the dummies, and interacting the 'peers' variable with the dummies. The proportion of teachers variable was also split into quartiles. The results were robust to these variations and thus they are not reported here.
} 
fifteen to nineteen years after promotion. The reasons we observe teachers for a specific time frame is not random; those teachers that have been in a rank for longer than others are certainly different from those that got promoted earlier. However, because we have the teacher fixed effect which captures the level effects, selection would only be a problem if the change in effort varies for teachers at different times in ways that are correlated with things that we have not been able to control for.

Finally, measurement error could be another potential source of bias. Here, we would be most concerned with measurement error in the evaluation scores, or with systematic bias in the evaluation scores. The systematic bias could arise if, for example, principals tend to inflate teachers' performance on their evaluations (perhaps as a source of encouragement). For these regressions, measurement error in the evaluation scores would only be a problem if it were systematic (correlated with the regressors). This would be the case if, for example, principals tended to overevaluate teachers' performance if the teacher had more experience or had been in a rank for longer. However, we do not find evidence for such effects in the data.

The final set of regressions examine the determinants of promotion, primarily to see whether evaluations are important for promotions, and if not, what does matter for promotion. Two sets of regressions are run for each of the five possible promotions (Primary 2 to Primary 1, Primary 1 to Primary high, Middle 3 to Middle 2, Middle 2 to Middle 1 and Middle 1 to Middle high); one is a set of Probit regressions, and the other is conditional fixed effects Logit. In both cases, the outcome is whether or not the teacher was promoted in that year (again we use the years 20032006) and the variable of interest is the evaluations. We include dummies for education level in that year, and then we progressively add: the proportion of teachers in the school at that rank, the average scores of all other teachers in the same rank, the dummy variables for years into a rank, the evaluation scores interacted with a dummy for the period before the key period of promotions and a dummy for the period following the key promotion period at that level (the key promotion period dummy being the omitted category), and the ability measures both separately and in the form of the index (we also include the timing of the tests variable in these latter regressions). In the Probit regressions we also include the teacher's age and a dummy for whether or not the teacher is female. Evaluations are included in two ways, the first is the evaluation score for that year ${ }^{14}$, and the second is a dummy for whether the evaluation score was 'excellent', and a dummy for whether the evaluation was 'good' (the omitted category is 'pass/fail'). Positive coefficients on the evaluation regressor or the dummies for excellent and good evaluations would indicate that evaluations do

\footnotetext{
${ }^{14}$ The evaluations are conducted in June of each school year, and promotions occur over the summer.
} 
matter for promotion. We expect that they will. The time after promotion dummies would serve to confirm the survival functions in terms of the timing of promotions.

Measurement error could be an issue with these regressions as well, as the evaluation scores are one of the regressors. Measurement error here could result in attenuation bias. Evaluations are likely an imperfect measure of teacher effort, but they do incorporate several dimensions of teacher effort, as they are based on student test scores, teacher attitude, attendance, and preparation.

\section{Results}

This section will present the results of the econometric analysis. We will begin with whether or not promotions are used as an incentive for effort in this context. Table 3 reports the results from estimating equation (6) for primary and middle school with the rank 'intern' or 'middle 3', and with the education level of primary school as the omitted categories.

We see that wages increase (relative to an intern or Middle 3 salary) by rank level for both primary and middle school; the coefficients on all rank dummies are positive and significant. Wages also decrease with experience (there is a correlation between experience and rank), non-linearly, and somewhat with education (only for those that have a four year degree or higher in primary school). The evaluation score is not important, indicating that what matters here is promotion to a higher rank. Furthermore, the magnitudes of the coefficients on the rank levels are greater than those on the education dummies. At the Primary high level, the increase in salary is more than $100 \%$ relative to an intern's salary. So, promotions are being used as incentives.

Furthermore, the salary differentials are highest where the promotion rates are closer to zero or one. The promotions with the promotion rates closest to one are Primary 2 to Primary 1 and Middle 3 to Middle 2. The promotion with the promotion rate closest to zero is Middle 1 to Middle high (although the promotion rate overall is just below $25 \%$ so it is not that low). Table 4 reports the average monthly salary (and its standard deviation) for teachers at each rank level. As expected, salaries increase with rank. The biggest jumps are from Primary 2 to Primary 1 , followed by Middle 3 to Middle 2, and then Middle 1 to Middle high. As Table 3 shows, the salary increases are $32.4 \%$, $25.1 \%$, and $21.5 \%$ respectively.

This confirms prediction 9: that salary differentials will be highest for promotion rates closer to zero or one. Models of promotion tournaments predict that salary increases are highest at the 
top level (CEO pay), and empirical studies do find evidence of this. This does not seem to be the case here. Although the salary at Middle high level is quite high, the difference between Middle high and other teachers is nowhere near that of a CEO compared to other employees in a firm. This is likely to do with the fact that this is a public sector context and teachers cannot be paid such high salaries.

Next, we look at effort incentives, specifically, over time and in response to competition. The regressions estimate equation (8), which is reproduced here for convenience:

$$
e_{i t}=\delta X_{i t}+\beta D_{i t}+\gamma C_{i t-1}+\delta A_{i t-1}+\omega_{i}+\varepsilon_{i t}
$$

We begin with the basic specification with only the time after promotion dummies included but no competition or ability variables. Figure 2 plots the coefficients on the years after promotion dummies for each of the six regressions (one for each rank level). These are the coefficients from Table $5^{15}$, which reports the results from the basic specification in which no competition or ability variables are included.

As the dummy for one year after promotion is the omitted category for each rank, the dummy coefficients for further years after promotion show effects relative to the first year after promotion. Figure 2 shows the trend in 'teacher effort' relative to that first year. We see that predictions 4 and 5 can be affirmed. For Primary 2, promotion to Primary 1 generally occurs after 45 years. Effort is high during this time but for those that are still at Primary 2 rank after that, effort is steadily decreasing. For Primary 1, promotion to Primary high is generally not until 10-15 years after promotion so effort is quite steady relative to the first year, even several years into the rank, and does show a bit of a drop afterwards. However, the coefficients are not significantly different from zero for Primary 2 or Primary 1. Primary high is the highest level for primary school and thus we naturally expect to see a drop off in effort, and quite a steady one is present here (this is prediction 10, there are no more promotions). Furthermore, the coefficients are highly significant, and the magnitude of the effect increases over time, with people that have been in the rank for 12 or more years receiving an evaluation score more than one point lower (from good to pass, for example). At the middle school 3 level, we see a steady decline in effort. This is likely due to the fact that most teachers are automatically promoted to Middle level 2 after 3-4 years. In this case, $p$ is close to one, and as the model predicts, there is very little incentive for effort (prediction 4). In Middle level 2 the average promotion time to Middle 2 is between 4 and 10 years (sometimes more) so this would

\footnotetext{
${ }^{15}$ There were too few observations at Middle high level, and with most of the variables dropping, results are not reported.
} 
explain the steady trend in effort that we see, after which there is a decline. Not many people are promoted from Middle level 1 to Middle high level (less than 25\%), and thus, the trend of the dummies here is a bit more erratic, we would expect more variation in teachers' responses here. Thus, in terms of when one becomes eligible for the next rank promotion, we do see effort behaving in the way that is expected: it declines for those passed over for promotion (particularly if passed over several times), it is very low for promotion probability close to one and for the highest rank, and tends to be steady if a promotion is in sight. Promotions do induce effort. However, the dummy coefficients in this specification are not often significant. When we control for competition and ability, the results are stronger.

When we begin to add the competition and ability variables, stronger patterns emerge. Figures 3 - 8 plot the dummy coefficients from Table 6, which reports the results from estimation of equation (8), our preferred specification with all the ability and competition variables included (the final column from each of Tables A2 - A7). ${ }^{16}$ The blue line plots the dummy coefficients for time after promotion from the basic specification discussed above, and the red line plots the dummy coefficients from the specification with the ability index quintile dummies and 'peers' variables included. From figures $3-8$, we see that adding these competition and ability measures changes the slope of the dummy trends, and from the appendix tables we see that ability appears to make more of a difference than the competition measures. In Primary 2 the sharp decline in effort becomes less pronounced once we control for competition or ability or both. In Primary 1, we see more effort around the main time of promotions, and then a sharper decline. Furthermore, the coefficients on the dummies between 8 and 13 years after promotion are now significant and of much greater magnitude indicating that there is actually an increase in effort relative to the first year after promotion. In Primary high, we see effort decline still, but less sharply.

In Middle 3 there is not much difference, except that the decrease in effort becomes more steady. In Middle 2 and Middle 1 there appears to be more effort once competition or ability (or both) are controlled for. At the Middle 2 level, the dummy coefficients once again become significant with the inclusion of the competition and ability variables, and the magnitudes greater. So for primary 2 and primary high, the decline in effort is less with the inclusion of the competition and/or ability measures. For the remainder of the rank levels, the increase in effort is accentuated. When we see that inclusion of these variables changes the magnitude and significance of the dummies, this could be because of a correlation between ability and time to promotion. The longer a teacher has been in a rank, the more likely it is that a teacher will be promoted. Furthermore, as

\footnotetext{
${ }^{16}$ Tables A2 - A7 in the appendix report results from all of the regressions for equation (8), with each column including a new competition or ability variable separately.
} 
time goes by, lower ability people tend to remain in the rank (or people that tend not to apply for promotion), so there is a negative correlation between number of years into a rank and ability (the selection problem mentioned earlier). This would explain why leaving ability out of the model would attenuate or accentuate the coefficients on the dummies, and this would be a mis-specification. Furthermore, at the Primary level, the dummy for the fourth quintile of the ability index is positive and significant, indicating that those with higher ability receive higher evaluation scores. At the Middle school level, the dummies for the fourth quintile are positive but insignificant. The dummies for the first and second quintiles are generally negative, and those for the fifth quintile are either negative or almost zero and insignificant. Thus, where one falls in the ability distribution is important, and it is those that are closer to the margin who have more incentive for effort, and for those either below or far above the margin, incentives are much lower. Inclusion of the proportion of teachers in the same rank and school variable does not add any information, the coefficients are never significantly different from zero. We will return to this later.

In terms of the competition variables, the effect that appears to stand out most is that of the teachers' previous evaluations (see column 2 of appendix tables A2-A7). At all rank levels except Middle 1, if a teacher received an 'excellent' evaluation score in the previous year, he/she receives a lower evaluation score in the current year. At the Primary 2 level, this effect is large, reducing the current year's evaluation score by half a point on average. At the Primary 1 and Middle 2 levels, the effect is also significant and reduces the current year's evaluation score by approximately 0.3. This would suggest that prediction 7 holds; a teacher that has been doing well in the past may update his/her information and subsequently slack off. It could also be evidence of principals skewing evaluation scores to motivate teachers. Alternatively, this could indicate mean reversion. After all, excellent evaluations are not easy to achieve and one cannot receive them all the time. However, as discussed previously, including lagged evaluation scores may induce bias. This effect disappears when we include the average score of all other teachers in the same school and rank in the previous year. The coefficient on this variable is very low and is insignificant for all rank levels except for Middle level one, where it is marginally significant (but positive). This may indicate either that teachers' effort does not respond to where they believe they fall in the skill distribution, or it could mean that teachers do not have information on other teachers' scores and thus are not able to update their beliefs. The teachers would have information on their history of evaluations, but not necessarily on other teachers' evaluations and probably not on the distribution of evaluation scores by rank, which is the relevant group they are competing against. This suggests that teachers likely do not have information on other teachers' ability rankings (it is very unlikely that a teacher would know the test scores of other teachers from their teacher tests). 
The finding that the number of competitors does not matter is surprising. To investigate prediction 8 further (the effect of the size of the pool of competitors), a regression was also run with the evaluation scores as the outcome again, but with all the observations pooled across ranks, and the number of teachers in the same rank in the same school interacted with the years after promotion dummies for all the rank levels. The regression is carried out with school-year fixed effects (which controls for the overall size of the school). Figure 9 (and Table A8) reports these results, with each point being the coefficient on the dummy for number of years after promotion interacted with the number of teachers in the same rank in the same school.

Prediction 8 states that for values of $p$ between $1 / 3$ and $2 / 3$, adding more contestants $(n)$ while keeping the ratio $\mathrm{k} / \mathrm{n}$ fixed ${ }^{17}$ will increase the MPE and thus incentives for effort are higher. The opposite is true for values outside this interval. Figure 9 supports prediction 8 . In Primary 2 almost everyone is promoted to Primary 1 , and this is generally within 4-10 years ( $p$ is high, likely higher than 2/3). None of the coefficients are significant here. In Primary 1 , it is unlikely that one will get a promotion before 5 or 6 years ( $p$ is low) as that is the minimum amount of time that one must wait to apply for promotion to Primary high. Before 5 years the coefficients are negative and significant and after 5 years there are positive coefficients. In fact, for 3 and 4 years after promotion, an increase in the number of competitors decreases the evaluation score by approximately half a point. Most promotions from Primary 1 to Primary high occur between 8 and 15 years after having been in Primary 1 rank, and we see positive coefficients in this range. After that, if a teacher is still in Primary 1 it may be unlikely that they will be promoted to Primary high and so $p$ (and effort incentives therefore) is low. For teachers in Middle 3 rank, the probability of promotion is quite high (everyone is promoted to Middle 2 at some point) but is highest between 2 and 4 years. Here again we see incentives increase. For Middle 2 level teachers the probability of promotion is again highest and is likely in the middle ranges between 5 and 10 years. We see weak evidence of incentives increasing here as well, with incentives dropping sharply if the competition increases for those still at Middle level 2 for more than 15 years, when $p$ is quite low. For Middle 1 to Middle high, not very many people get promoted at all (less than a quarter). However, for those that do get promoted it is usually between 8 and 15 years and once again we see incentives increase with the number of teachers. The magnitude for 9 and 10 years after promotion is quite high, with an increase in the number of teachers increasing the evaluation score by 1.74 . In this case it seems that competition really matters. It appears that prediction 8 fits this data well.

\footnotetext{
${ }^{17} \mathrm{k} / \mathrm{n}$ is fixed here because it is determined by the district through quotas for ranks in each school.
} 
In terms of competition then, what seems to be occurring is that the number of competitors affects one's effort incentives (depending on the timing, which is what determines one's probability of promotion), but teachers are not able to adequately update their beliefs regarding where they fall in the ability distribution relative to others. As discussed in section III, when teachers have less information about their ability, this can increase incentives, and so promotions here may serve as an even more effective sorting and incentive mechanism.

In terms of effort and wages, the model predicts that effort will be highest where the wage jump is largest. We do see effort increasing up to the time of the most promotions for Primary 2 to Primary 1, but we see a decline in effort for Middle 3 to Middle 2. This may be because the promotion rate is too close to one. The large increase in salary from Middle 1 to Middle high may also help explain why we do see effort at this rank level even though the promotion rate is low.

The final set of regressions looks at the determinants of promotion to see whether evaluations matter for promotion. If they do, then promotions provide effective incentives for effort. A binary outcome is used (promoted or not promoted) for the years 2003-2006. Tables A9 A18 report the results. Tables A9 - A13 report Probit specifications for each promotion (Primary 2 to Primary 1, Primary 1 to Primary high, Middle 3 to Middle 2, Middle 2 to Middle 1 , and Middle 1 to Middle high), and tables A14 - A18 report conditional fixed effects Logit results ${ }^{18}$. In the Probit regressions, for Primary 1, Middle 3 and Middle 2, we see that there is a positive and significant (albeit marginally significant) effect of evaluation scores on probability of promotion. For Primary 1 and Middle 3, it matters even more if you received an excellent evaluation score. In the conditional fixed effects Logit regressions, this effect disappears. However, the conditional fixed effects Logit regression omits those observations for whom there was no promotion between 2003 and 2006 and thus standard errors are larger. It also uses only within-person variation. To further disentangle the effects of evaluations, each rank was split into three periods: the pre-promotion period, the key promotion period, and the post-promotion period, and a dummy was created for each one. The key promotion period was determined as the years for which majority of promotions occur at that rank. For Primary high and Middle high, the dummies were simply split into three equal sized groups since there are no more promotions at those levels. In column 7 of each of tables A9 - A18, results are reported for the specification with evaluation scores interacted with the dummy for the prepromotion period and that of the post-promotion period (leaving the key promotion period as the omitted category). In both the Probit and the Logit regressions, positive evaluations before the

\footnotetext{
${ }^{18}$ Marginal effects are not reported for conditional Logit, the presence of the fixed effect makes these difficult to interpret (Cameron and Trivedi, 2009). Instead, coefficients are reported so we cannot comment on the size of the effects, only the direction and level of significance.
} 
critical period affect the probability of promotion less than evaluations during the critical promotion period at each level. In the Logit regressions, the evaluations after the critical period have a positive and significant effect. In the Probit regressions, this remains the case, except in Primary 2 and Middle 3 where a higher evaluation has a lower impact on your probability of promotion in the period after the critical period of promotions than during the critical period. For Primary 1 , Middle 2 , and Middle 1 you can still get promoted after a few years. For Primary 2 and Middle 3 if you miss the key promotion period you may not get promoted. The magnitude of the coefficients is small, the largest being a decrease of $7 \%$ in the pre-promotion period for Middle 3. So, evaluations do matter, and they matter most around the key promotion times. This is evidence that promotions provide effort incentives.

These regressions also confirm that the timing of promotions for each rank is in accordance with the Kaplan-Meier survival functions and Table $\mathrm{A} 1$ as evidenced by the dummy coefficients in column 6 of each table. Furthermore, the number of teachers in one's rank appears to matter in some cases. In Primary 2 and Middle 3, the more teachers one is competing against, the lower the probability of promotion. This is interesting because these are the levels with the highest probability of promotion overall; most teachers do get promoted. For Middle 2 to Middle 1 , the teachers variable is positive in the Logit regressions, so the more teachers, the higher the probability of promotion. This could be an effort effect; perhaps in Primary 2 and Middle 3, teachers know that they will most likely get promoted and slack off, even if there are a lot of teachers they are competing against. For Middle 2 to Middle 1, not everyone is promoted and thus teachers must put in effort to be promoted and if there are more teachers, they must work even harder. We did see that effort in Primary 2 and Middle 3 drops off but that it remains high and steady for Middle 2.

\section{Conclusions}

This paper has attempted to gain insight into the way in which the system of promotions and annual evaluations in China affects teachers' effort incentives. A model of promotions as a sorting and as an incentive mechanism was developed, that modelled teachers as having a particular skill level, as well as discussed beliefs over one's skill level relative to others in their cohort. The model included a performance measure measured with error. The teacher's first order condition was derived and simplified in order to study how the marginal probability of effort changed with respect to the number of teachers, the probability of promotion, and beliefs about skill. A number of predictions were established, and data from the Gansu Survey of Children and Families (GSCF) was used to test the predictions of the model. 
In summary, many of the predictions of the model are evident in the data. First, promotions are used for incentives amongst teachers in China. Rank levels are the strongest predictors of variation in monthly wage. Furthermore, predictions 1 and 9 are also apparent here. The larger the salary differential (combined with the probability of promotion being closer to $1 / 2$ ), the higher the effort (Primary 1 to Primary high and Middle 2 to Middle 1), and for promotion rates closer to zero or one, the salary differentials are greatest (Primary 2 to Primary 1 and Middle 3 to Middle 2).

In addition, promotions do elicit effort. When a teacher becomes eligible for promotion, he/she exhibits higher effort in the form of higher evaluation scores. When promotion is not likely either because it is too soon after the most recent promotion, or the teacher has been in the rank for far too long, or because there are no more promotions, effort drops significantly (predictions 4, 5 and 10). The number of teachers that one is competing with matters. If the probability of promotion is very low or very high, then more competition implies lower effort, and if the probability of promotion is between $1 / 3$ and $2 / 3$, effort is higher (prediction 8 ). The harder it is to obtain the promotion and the more competitors, the harder one works for promotion. Teachers that have been doing well in the past tend to slack off. However, they are not able to update their beliefs on their relative position in the ability distribution, likely because other teachers' evaluation scores (or other ability variables) by rank are not made public. If a teacher receives an excellent evaluation in the previous year, he/she will believe that their ability is likely above the $1-p^{\text {th }}$ percentile and will have lower incentives (predictions 4 and 7). The fact that there is less information available to them (not reporting everyone's scores) means that it is possible that both those farther ahead and farther behind do not know exactly where they stand relative to others and this would mean that they believe they are closer to the margin than they would if all scores were revealed. Perhaps this is the reason (combined with the relatively high salary increase) that we see effort in Middle 1 even though only a few are promoted to Middle high level. Evaluations seem to matter for promotion, and particularly during the critical time for promotions. Thus, the promotions do serve as effective incentives for effort.

These findings suggest several policy implications. The most important is that incentivizing teachers based on performance pay may not be necessary. The use of bonuses amongst this sample of teachers is very low, however, the system of promotions seems to be incentive enough for effort in many cases. The fact that effort drops steadily in the highest ranks may make a case for using performance pay at these levels to keep motivation high, but at lower levels it may not be necessary. However, this system is quite complex and may be difficult to implement in some places. The culture and traditions surrounding hiring and promotion of teachers may not be conducive to such a 
system; in places in which meritocracy is appreciated, such a system may fare better. The findings on salary levels and on the number of teachers in a contest would also provide policy makers with an idea as to how to mould the salary structure to optimally motivate effort, and would provide some insight into optimal school size and how to split teachers into contests. Finally, these results also help explain the success of the Chinese economic reforms in general. The reforms in the government in particular were very much tied to bureaucratic performance and merit-based promotions. The system is quite sophisticated and understudied, but can provide examples of good practice for other contexts.

There are many extensions to this work that one can envisage. First, data on evaluation scores of teachers in subsequent rounds of the survey would enrich the analysis by ameliorating the selection problem that was noted. Furthermore, better data on teachers' ability would provide better proxies. Second, the fact that the evaluations can be based on different aspects of teaching merits further study, which is outside of the scope of this paper. It may be the case that different types of evaluations elicit different types of effort among teachers. Such a study would need to adequately control for how the choice of evaluation system is determined. Finally, in order to make more specific recommendations, such studies should be carried out in other contexts and/or countries so that external validity can be discussed, and policy implications made clearer. 


\section{References}

Abubakar, I. A. (1983). The education, training and supply of technical teachers for schools and colleges in Nigeria. University of Wales.

Baker, G. P., Jensen, M. C., \& Murphy, K. J. (1988). Compensation and incentives: practice vs. theory. Journal of Finance, Vol. 43, pp. 593-616.

Baker, G., Gibbons, R., \& Murphy, K. J. (1994). Subjective performance measures in optimal incentive contracts. Quarterly Journal of Economics, Vol. 109, pp. 1125-1156.

Baker, G., Gibbs, M., \& Holmstrom, B. (1994a). The internal economics of the firm: evidence from personnel data. Quarterly Journal of Economics, Vol. 109, pp. 881-919.

Baker, G., Gibbs, M., \& Holmstrom, B. (1994b). The wage policy of a firm. Quarterly Journal of Economics, Vol. 109, pp. 921-955.

Black, P. A., \& Hosking, S. G. (1997). The teacher crisis in South Africa: Quitting, shirking, and inferior substitution. South African Journal of Economics, Vol. 65, No. 4, pp. 500-509.

Bognanno, M. (2001). Corporate Tournaments. Journal of Labour Economics, Vol. 19, No. 2, pp. 290315.

Cameron, C., \& Trivedi, P. (2009). Microeconometrics using Stata. College Station, Texas: Stata Press.

Campbell, D. (2008). Non-financial performance measures and promotion-based incentives. Journal of Accounting Research , Vol. 46, No. 2, pp. 297-332.

Chapman, D. W. (1983). A model of the influences on teacher retention. Journal of Teacher Education, Vol. 34, No. 5, pp. 43-49.

Chivore, B. S. (1985). Recruitment and training of non-graduate secondary teachers in Zimbabwe. Institute of Education, University of London .

Ding, W., \& Lehrer, S. F. (2001). The Optimal Policy to Reward the Value Added by Educators: Theory and Evidence from China. mimeo .

Dolton, P. J. (2006). Teacher Supply. In E. A. Hanushek, \& F. Welch, Handbook of the Economics of Education, Volume 2 (pp. pp. 1078-1161). Amsterdam: Elsevier B.V.

Duflo, E., \& Hanna, R. (2005). Monitoring Works: Getting teachers to come to school. NBER Working Paper Series, Working Paper No. 11880.

Fairburn, J. A., \& Malcolmson, J. M. (2001). Performance, Promotion, and the Peter Principle. The Review of Economic Studies, Vol. 68, No. 1, pp. 45-66.

Figlio, D. N., \& Kenny, L. (2006). Individual Teacher Incentives and Student Performance. NBER Working Paper Series, Working Paper 12627. 
Figlio, D., \& Getzler, L. S. (2002). Accountability, Ability and Disability: Gaming The System. NBER Working Paper Series, Working Paper No. 9307.

Figlio, D., \& Winicki, J. (2002). Food for Thought? The Effects of School Accountability Plans on School Nutrition. NBER Working Paper Series, Working Paper No. 9319.

Gibbons, R., \& M, W. (2006). Enriching a Theory of Wage and Promotion Dynamics inside Firms. Journal of Labour Economics, Vol. 24, No. 1, pp. 59-107.

Gibbons, R., \& Waldman, M. (1999). Careers in organizations: theory and evidence. Handbook of Labor Economics, Chapter 36, Vol. 3B.

Gibbs, M. J. (1991). An Economic Approach to Process in Pay and Performance Appraisals. mimeo .

Gibbs, M. J. (1995). Incentive Compensation in a Corporate Hierarchy. Journal of Accounting and Economics, Vol. 19, No. 2-3, pp. 247-77.

Gibbs, M. J. (1990). Promotions and Incentives : Tournaments Vs. Standards. Boston: Division of Research Harvard Business School, Working paper 90-064.

Gibbs, M. J. (1989). Promotions, Compensation, and Firm Organization. PhD Thesis, University of Chicago.

Gibbs, M. J. (1994). Testing Tournaments? An Appraisal of the Theory and Evidence. Labor Law Journal, Vol. 45, NO. 8, pp. 493.

Glewwe, P. (2002). Schools and skills in developing countries: education policies and socio-economic outcomes. Journal of Economic Literature, Vol. XL, pp. 436-482.

Glewwe, P., \& Kremer, M. (2006). Schools, Teachers and Education Outcomes in Developing Countries. In E. A. Hanushek, \& F. e. Welch, The Handbook of the Economics of Education. Amsterdam: Elsevier .

Glewwe, P., llias, N., \& Kremerer, M. (2003). Teacher Incentives. NBER Working Paper Series, Working Paper No. 9671.

Hedges, J. (2002). The importance of posting and interaction with the education bureaucracy in becoming a teacher in Ghana. International Journal of Educational Development, Vol. 22, pp. 353366.

Holmstrom, B. (1979). Moral hazard and observability. Bell Journal of Economics, Vol. 9, pp. 74-91.

Holmstrom, B., \& Milgrom, P. (1991). Multitask principal-agent analyses: incentive contracts, asset ownership and job design. Journal of Law, Economics, and Organization, Vol. 7, pp. 24-52.

Jacob, B., \& Levitt, S. (2002). Rotten Apples: An Investigation of the Prevalence and Predictors of Teacher Cheating. Quarterly Journal of Economics .

Knoeber, C. R., \& Thurman, W. N. (1994). Testing the Theory of Tournaments: An Empirical Analysis of Broiler Production. Journal of Labor Economics , Vol. 12, No. 2, pp. 155-179. 
Komenan, A., \& Grootaert, C. (1990). Pay differences between teachers and other occupations: Some empirical evidence from Cote d'Ivoire. Economics of Education Review , Vol. 9, No. 3, pp. 209217.

Kwon, I. (2006). Incentives, wages, and promotions: theory and evidence. RAND Journal of Economics, Vol. 37, No. 1, pp. 100-120.

Lavy, V. (2002). Evaluating the Effect of Teachers' Group Performance Incentives on Pupil Achievement. Journal of Political Economy, Vol. 110, No. 6, pp. 1286-1317.

Lavy, V. (2003). Paying for Performance: The Effect of Individual Financial Incentives on Teachers' Productivity and Students' Scholastic Outcomes. mimeo .

Lazear, E. P. (1992). The job as a concept. In e. W. Bruns, Pel-formance measurement, evaluations, and incentives (pp. pp. 183-215). Boston: Harvard University Press.

Lazear, E. P., \& Rosen, S. (1981). Rank- Order Tournaments as Optimum Labour Contracts. NBER Working Paper Series, Working paper No. 401.

Macdonald, D. (1999). Teacher attrition: a review of literature. Teaching and Teacher Education , Vol. 15.

MacLeod, W. B., \& Malcomson, J. M. (1988). Reputation and hierarchy in dynamic models of employment. Journal of Political Economy, Vol. 96, pp. 832-854.

Malcolmson, J. M. (1984). Work incentives, hierarchy, and internal labor markets. Journal of Political Economy, Vol. 92, pp. 486-507.

McEwan, P. (1999). Recruitment of rural teachers in developing countries: an economic analysis . Teaching and Teacher Education , Vol. 15, No. 8, pp. 849-859.

Medoff, J., \& Abraham, K. (1981). Are those paid more really more productive? Journal of Human Resources, Vol. 16, pp. 186-216.

Medoff, J., \& Abraham, K. (1980). Experience, performance, and earnings. Quarterly Journal of Economics, Vol. 95, pp. 703-736.

Milgrom, P. (1988). Employment contracts, influence activities and efficient organization design. Journal of Political Economy, Vol. 96, pp.42-60.

Milgrom, P., \& Roberts, J. (1988). An economic approach to influence activities in organizations. American Journal of Sociology, Vol. 94, pp. S154-S179.

Mirrlees, J. (1974). Notes on welfare economics, information, and uncertainty. In M. Balch, D. McFadden, \& S. e. Wu, Essays on economic behavior under uncertainty (pp. pp. 243-258). Amsterdam: North-Holland.

Mirrlees, J. (1976). The optimal structure of incentives and authority within an organization. Bell Journal of Economics, Vol. 7, pp. 105-131. 
Mulkeen, A. e. (2007). Recruiting, retaining and retraining secondary school teachers and principals in Sub-Saharan Africa. World Bank Human Development Series, Working Paper No. 99.

Muralidharan, K., \& Sundararaman, V. (2009). Teacher performance pay: Experiemental evidence from India. NBER Working Paper Series, Working Paper No. 15323.

Nalebuff, B. J., \& Stiglitz, J. E. (1983). Prizes and incentives: towards a general theory of compensation and competition. Bell Journal of Economics, Vol. 14, pp. 21-43.

Park, A., \& Hannum, E. (2001). Do Teacher Characteristics Affect Student Learning in Developing Countries?: Evidence from Matched Teacher-Student Data from Rural China. mimeo .

Park, A., Hannum, E., \& eds. (2007). Education and Reform in China. London: Routledge.

Perry, C. (2007). MoESS/GES Teacher Supply and Demand Forecasting Model - Final Report. Report prepared for the Ministry of Education, Ghana .

Podgursky, M. J., \& Springer, M. G. (2006). Teacher Performance Pay: A Review. National Centre on Performance Incentives, working paper.

Prendergast, C., \& Topel, R. H. (1996). Favoritismin organizations. Journal of Political Economy , Vol. 104, pp.958-978.

Rosen, S. (1982). Authority, control, and the distribution of earnings. Bell Journal of Economics, Vol. 13, pp. 311--323.

Rosen, S. (1986). Prizes and incentives in elimination tournaments. American Economic Review , Vol. 76, pp. 701-715.

Sattinger, M. (1975). Comparative advantage and the distributions of earnings and abilities. Econometrica, Vol. 43, pp. 455-468.

Shavell, S. (1979). Risk sharing and incentives in the principal and agent relationship. Bell Journal of Economics, Vol. 10, pp. 55-73.

Waldman, M. (1984). Worker allocation, hierarchies and the wage distribution. Review of Economic Studies, Vol. 51, pp. 95-109.

Zhao, M., \& Glewwe, P. (2009). What determines basic school attainment in developing countries? Evidence from rural China. Gansu Survey of Children and Families Papers, Working Paper 13. 


\section{Figures}

Figure 1. Kaplan-Meier survival functions for number of years until promotion
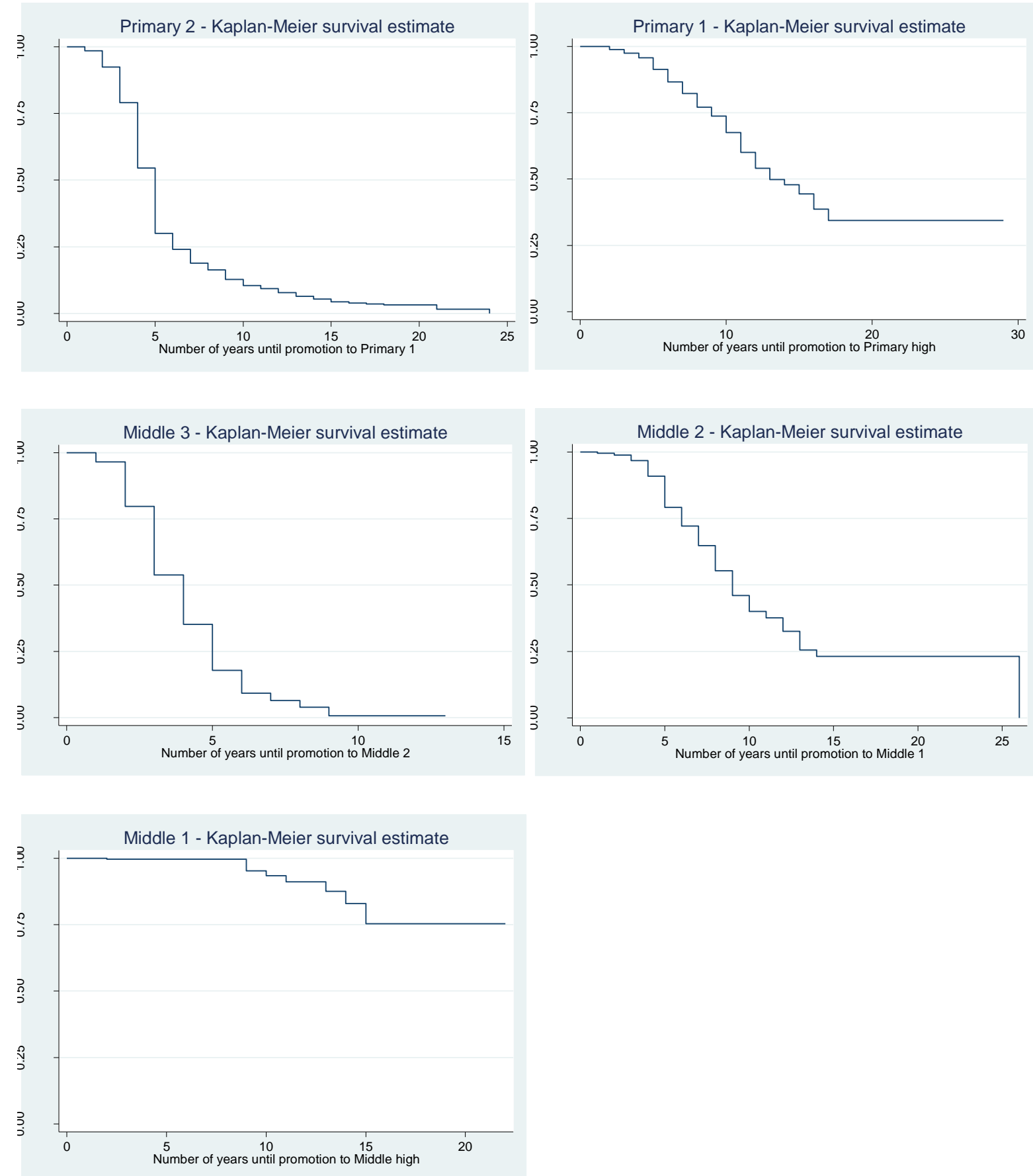
Figure 2. Dummy coefficients, Primary 1 - Middle 1

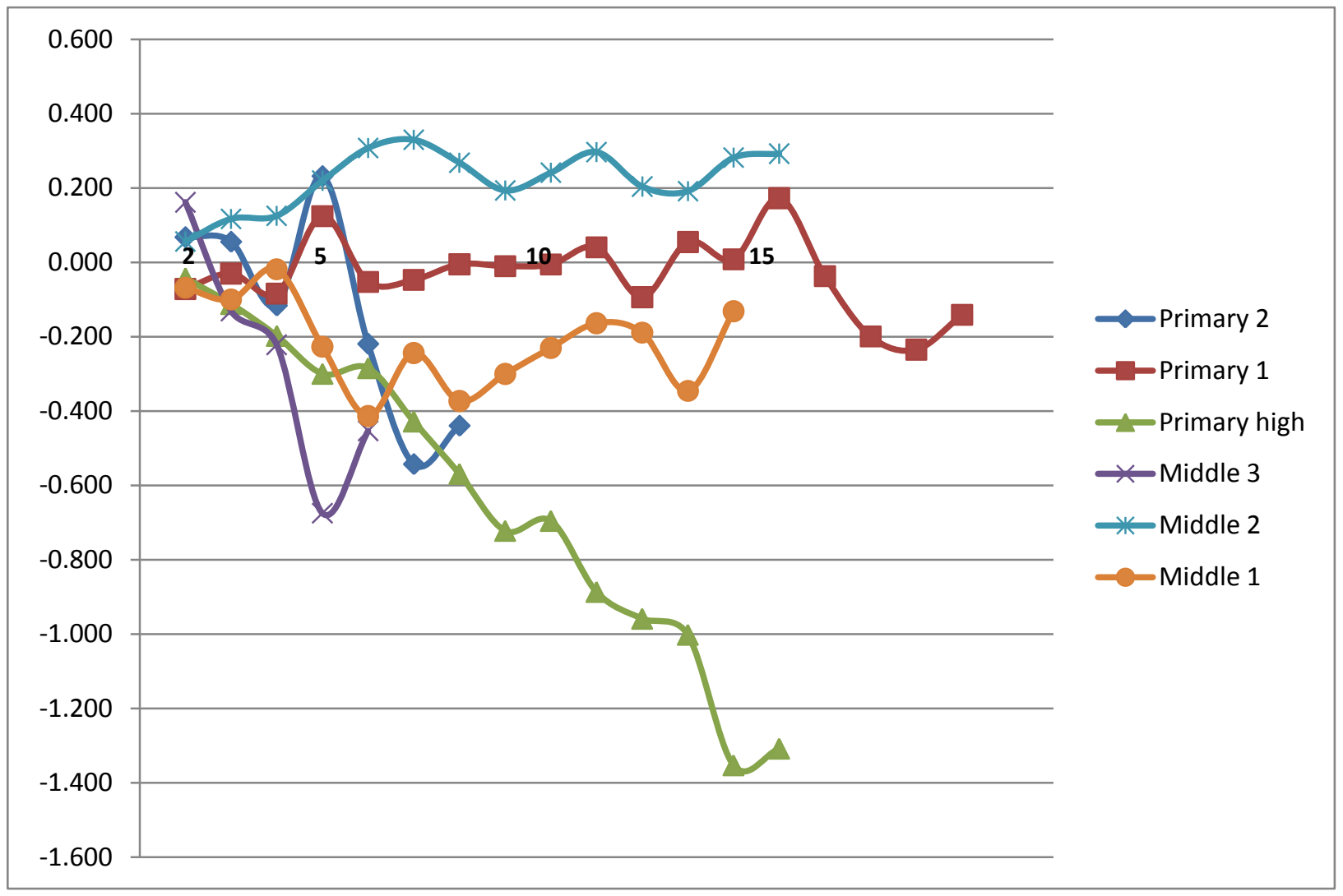


Figure 3. Primary 2

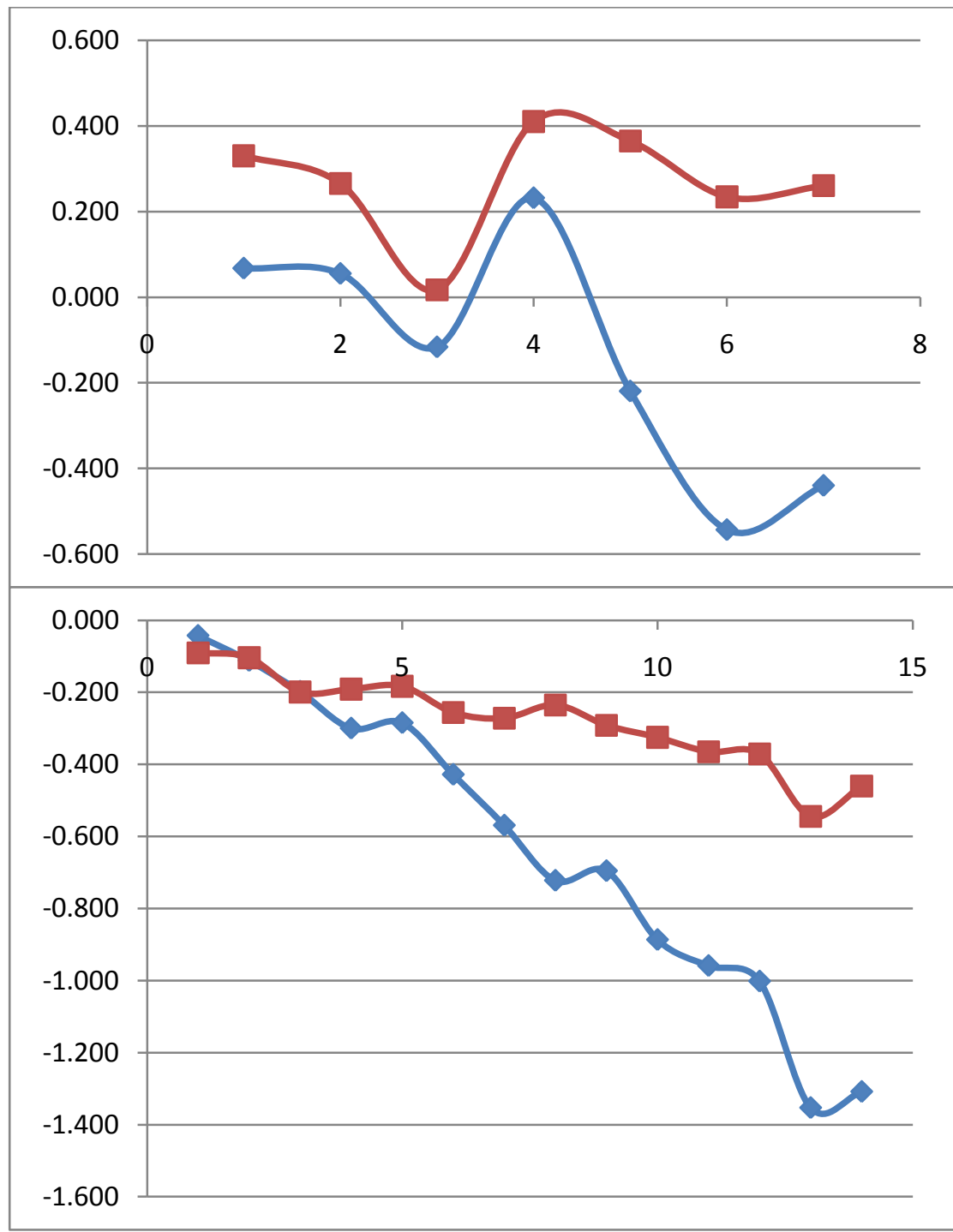

Figure 5. Primary high
Figure 4. Primary 1

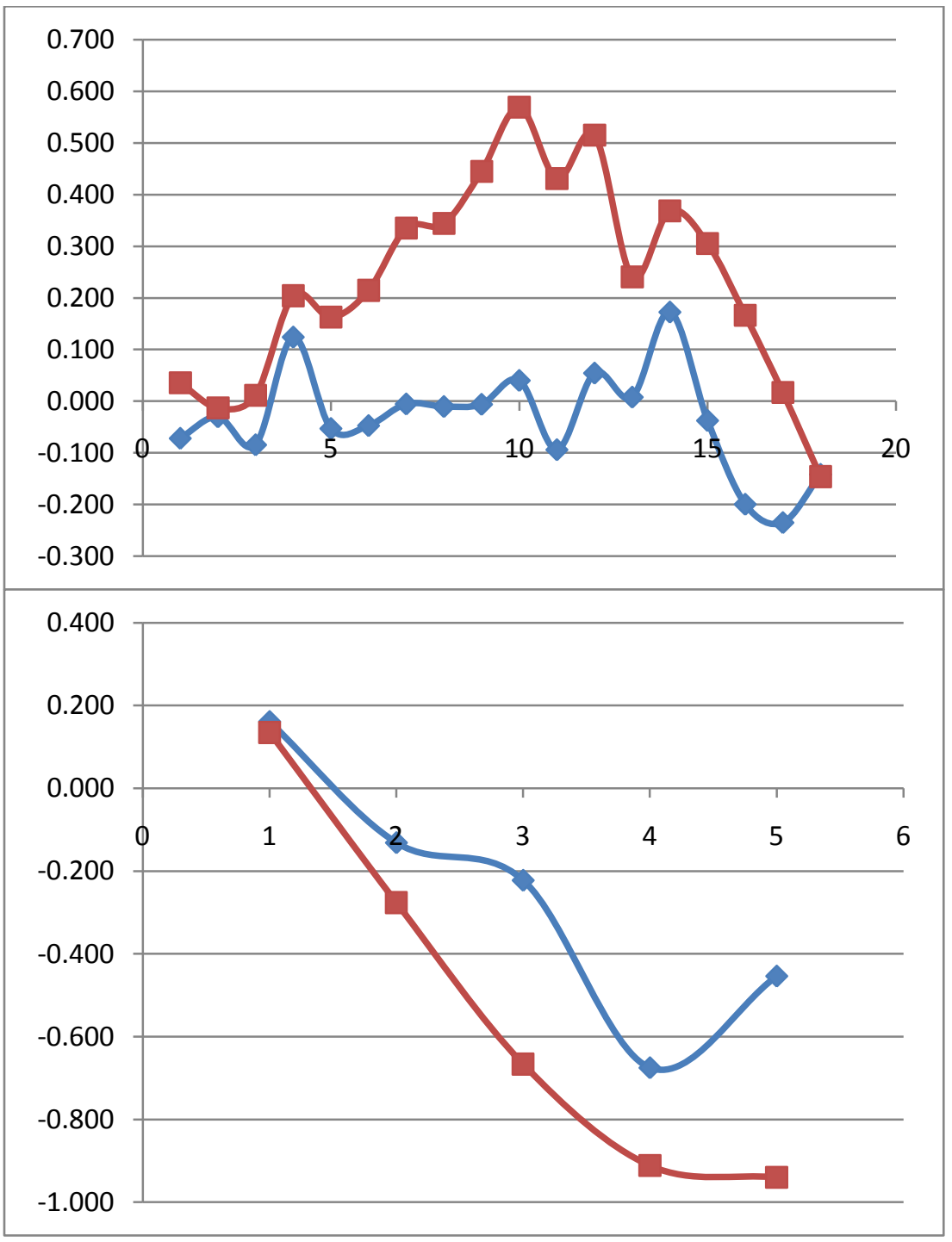

Figure 6. Middle 3 
Figure 7. Middle 2

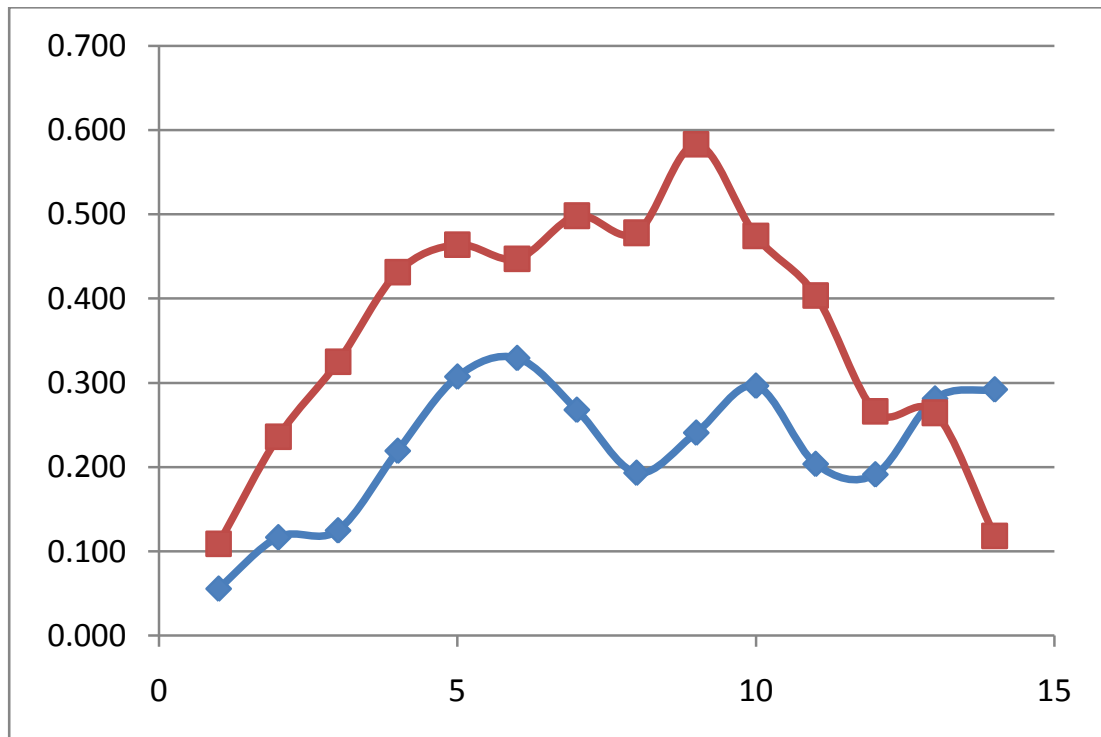

Figure 8. Middle 1

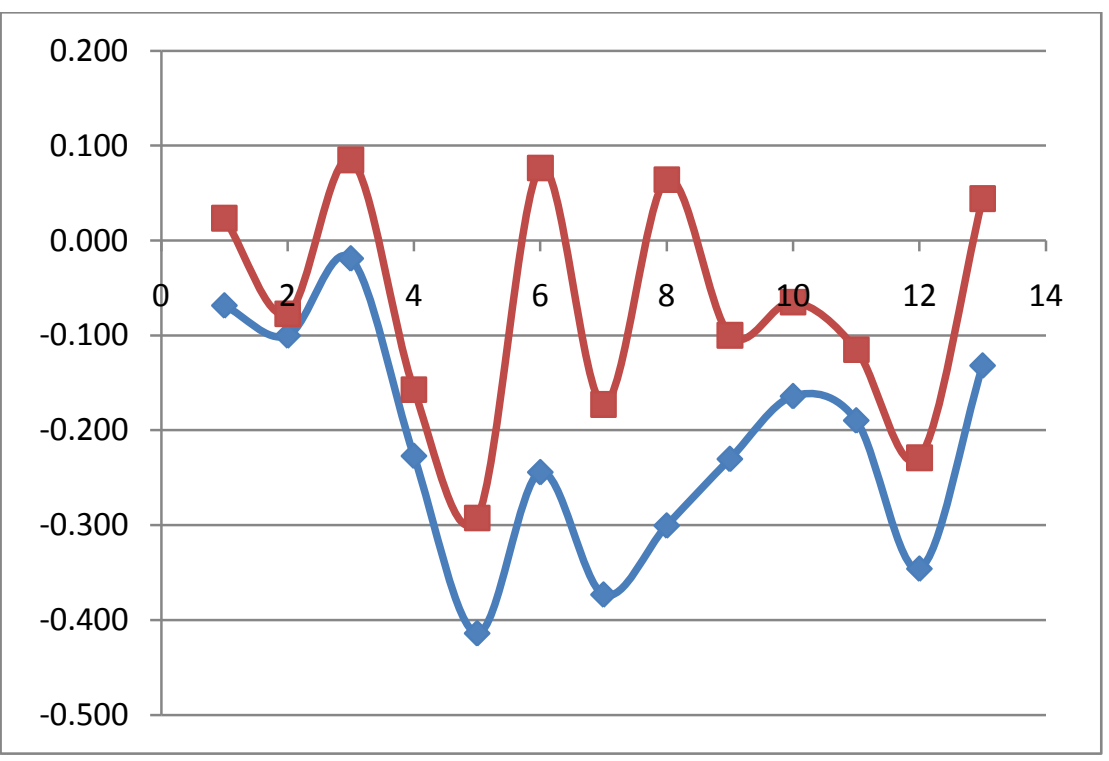


Figure 9. Proportion of teachers in the same rank

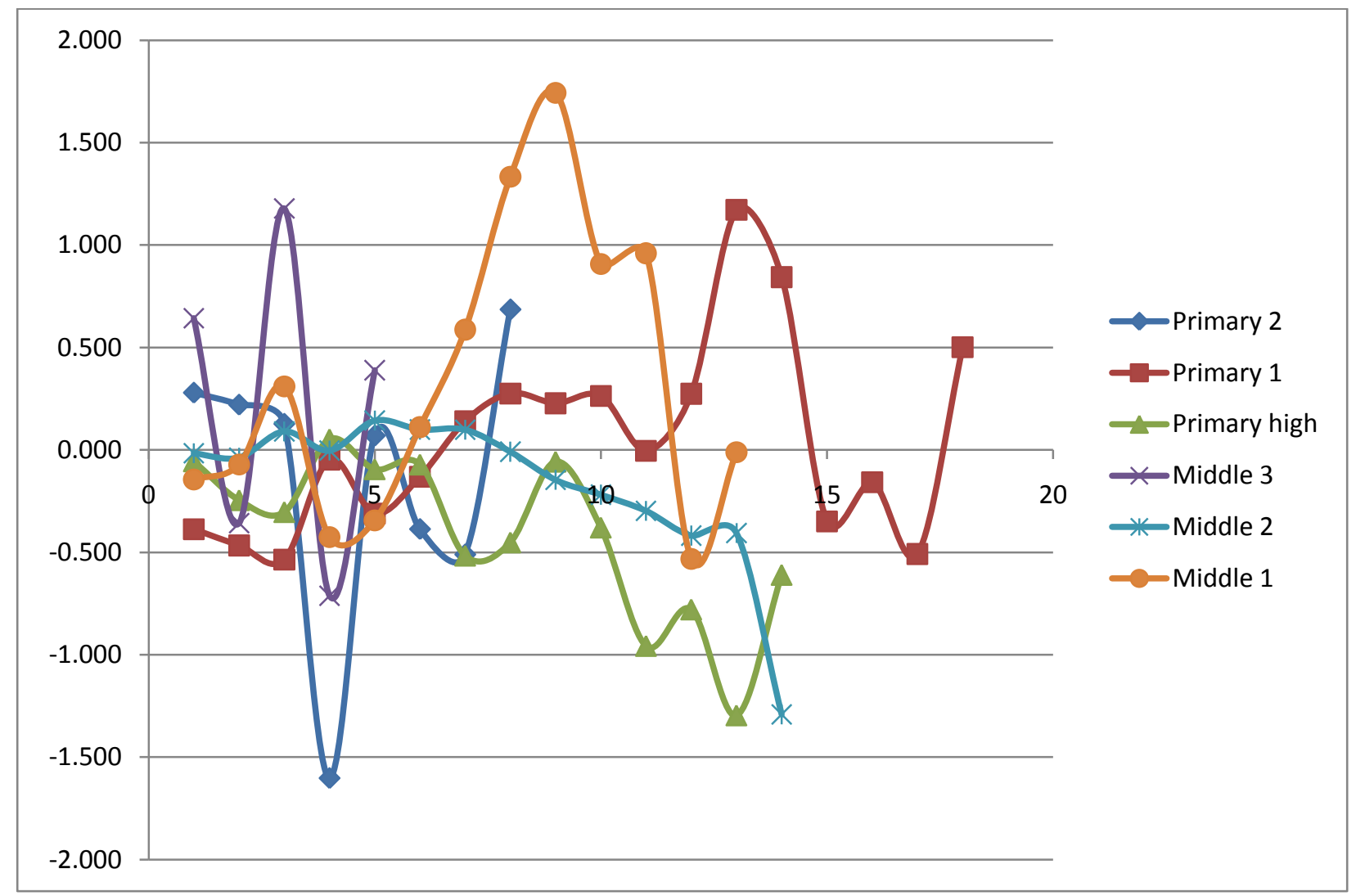


Table 1. Characteristics of Teachers in the sample, Round 3 (2007)

\begin{tabular}{|c|c|c|c|c|c|c|c|c|}
\hline & $\begin{array}{c}\text { No } \\
\text { title/Intern }\end{array}$ & $\begin{array}{c}\text { Primary } \\
2 \\
\end{array}$ & $\begin{array}{c}\text { Primary } \\
1 \\
\end{array}$ & $\begin{array}{l}\text { Primary } \\
\text { high }\end{array}$ & $\begin{array}{c}\text { Middle } \\
\mathbf{3}\end{array}$ & $\begin{array}{c}\text { Middle } \\
2 \\
\end{array}$ & $\begin{array}{c}\text { Middle } \\
1 \\
\end{array}$ & $\begin{array}{l}\text { Middle } \\
\text { high }\end{array}$ \\
\hline \multicolumn{9}{|l|}{ Number of teachers } \\
\hline Total & 331 & 163 & 553 & 354 & 133 & 525 & 281 & 13 \\
\hline Male & $43 \%$ & $42 \%$ & $55 \%$ & $75 \%$ & $51 \%$ & $63 \%$ & $83 \%$ & $85 \%$ \\
\hline Female & $57 \%$ & $58 \%$ & $45 \%$ & $25 \%$ & $49 \%$ & $37 \%$ & $17 \%$ & $15 \%$ \\
\hline \multicolumn{9}{|l|}{ Basic characteristics } \\
\hline Average Age & 29.09 & 28.3 & 36.7 & 48 & 26.8 & 32.3 & 40.6 & 47.2 \\
\hline Average Years teaching & 7 & 7 & 16.3 & 27.6 & 4 & 10.1 & 19.7 & 27.6 \\
\hline Education - primary & $1 \%$ & $1 \%$ & $0 \%$ & $0 \%$ & $0 \%$ & $0 \%$ & $0 \%$ & $0 \%$ \\
\hline Education - middle school & $5 \%$ & $2 \%$ & $3 \%$ & $3 \%$ & $1 \%$ & $2 \%$ & $1 \%$ & $0 \%$ \\
\hline $\begin{array}{l}\text { Education - high school } \\
\text { Education - vocational }\end{array}$ & $23 \%$ & $7 \%$ & $22 \%$ & $48 \%$ & $2 \%$ & $2 \%$ & $10 \%$ & $0 \%$ \\
\hline middle & $20 \%$ & $55 \%$ & $63 \%$ & $45 \%$ & $13 \%$ & $32 \%$ & $47 \%$ & $54 \%$ \\
\hline $\begin{array}{l}\text { Education - vocational tech } \\
\text { Education - vocational }\end{array}$ & $1 \%$ & $1 \%$ & $0 \%$ & $0 \%$ & $0 \%$ & $0 \%$ & $1 \%$ & $0 \%$ \\
\hline college & $45 \%$ & $34 \%$ & $12 \%$ & $4 \%$ & $83 \%$ & $57 \%$ & $38 \%$ & $46 \%$ \\
\hline Education - four year degree & $6 \%$ & $1 \%$ & $0 \%$ & $0 \%$ & $2 \%$ & $7 \%$ & $3 \%$ & $0 \%$ \\
\hline \multicolumn{9}{|l|}{ Ability measures } \\
\hline Education test score (90-99) & $12.1 \%$ & $11.8 \%$ & $18.2 \%$ & $17.0 \%$ & $10.8 \%$ & $17.8 \%$ & $15.1 \%$ & $40 \%$ \\
\hline Education test score (80-89) & $60.1 \%$ & $59.7 \%$ & $59.5 \%$ & $59.2 \%$ & $59.2 \%$ & $60.8 \%$ & $65.5 \%$ & $60 \%$ \\
\hline Education test score (70-79) & $21.4 \%$ & $18.8 \%$ & $19.8 \%$ & $20.3 \%$ & $26.9 \%$ & $17.6 \%$ & $15.9 \%$ & - \\
\hline $\begin{array}{l}\text { Education test score (60-69) } \\
\text { Education test score (below }\end{array}$ & $5.7 \%$ & $8.3 \%$ & $2.5 \%$ & $3.2 \%$ & $2.3 \%$ & $3.9 \%$ & $2.8 \%$ & - \\
\hline 60$)$ & $0.7 \%$ & $1.4 \%$ & - & $0.3 \%$ & $0.8 \%$ & - & $0.8 \%$ & - \\
\hline Psychology test score (90-99) & $11.9 \%$ & $19.3 \%$ & $15.8 \%$ & $15.0 \%$ & $11.7 \%$ & $17.3 \%$ & $13.9 \%$ & $30 \%$ \\
\hline Psychology test score (80-89) & $53.2 \%$ & $47.6 \%$ & $57.6 \%$ & $54.6 \%$ & $50.0 \%$ & $55.8 \%$ & $55.6 \%$ & $70 \%$ \\
\hline Psychology test score (70-79) & $23.7 \%$ & $22.1 \%$ & $21.8 \%$ & $25.2 \%$ & $28.9 \%$ & $19.6 \%$ & $25.8 \%$ & - \\
\hline Psychology test score (60-69) & $10.1 \%$ & $9.7 \%$ & $4.8 \%$ & $4.9 \%$ & $9.4 \%$ & $7.3 \%$ & $4.0 \%$ & - \\
\hline \multicolumn{9}{|l|}{ Psychology test score (below } \\
\hline 60$)$ & $1.1 \%$ & $1.4 \%$ & - & $0.3 \%$ & - & - & $0.8 \%$ & - \\
\hline Language test score (90-99) & $2.9 \%$ & $0.7 \%$ & $1.2 \%$ & $4.8 \%$ & $3.8 \%$ & $2.0 \%$ & $3.0 \%$ & $20 \%$ \\
\hline Language test score $(80-89)$ & $38.5 \%$ & $45.8 \%$ & $36.8 \%$ & $31.8 \%$ & $42.4 \%$ & $38.9 \%$ & $31.6 \%$ & $40 \%$ \\
\hline Language test score (70-79) & $11.2 \%$ & $8.5 \%$ & $15.0 \%$ & $21.8 \%$ & $10.6 \%$ & $10.3 \%$ & $16.2 \%$ & $20 \%$ \\
\hline $\begin{array}{l}\text { Language test score (60-69) } \\
\text { Language test score (below }\end{array}$ & $47.1 \%$ & $44.4 \%$ & $41.8 \%$ & $33.3 \%$ & $40.9 \%$ & $46.2 \%$ & $37.2 \%$ & $20 \%$ \\
\hline 60$)$ & $0.4 \%$ & $0.7 \%$ & $5.1 \%$ & $8.3 \%$ & $2.3 \%$ & $2.6 \%$ & $12.0 \%$ & - \\
\hline $\begin{array}{l}\text { Number of awards received } \\
\text { (avg) }\end{array}$ & 2.3 & 2.85 & 5.16 & 6.15 & 1.47 & 3.65 & 6.52 & 10.08 \\
\hline \multicolumn{9}{|l|}{ Time use } \\
\hline $\begin{array}{l}\text { Hours per week spent } \\
\text { grading (avg) } \\
\text { Hours per week on lesson }\end{array}$ & 10.4 & 11.62 & 9.62 & 9.24 & 9.92 & 9.13 & 9.16 & 7.38 \\
\hline plans (avg) & 9.98 & 9.66 & 9.18 & 9.11 & 9.61 & 9.23 & 9.7 & 7.92 \\
\hline Published a paper & $12.1 \%$ & $25.2 \%$ & $46.5 \%$ & $35.9 \%$ & $17.3 \%$ & $45.9 \%$ & $57.3 \%$ & $100.0 \%$ \\
\hline
\end{tabular}


(proportion)

Number of classes taught

(avg)

students (avg)

17.57

19.34

18.05

17.79

14.34

13.7

13.13

9.84

14.18

13.67

12.09

11.24

14.58

$12.82 \quad 12.44$

7.03

Table 2. Evaluation scores of teachers by rank (2003-2006) ${ }^{19}$

\begin{tabular}{lcccccc}
\hline & \multicolumn{2}{c}{ Primary 2 } & \multicolumn{2}{c}{ Primary 1 } & \multicolumn{2}{c}{ Primary high } \\
\hline & Number & Percent & Number & Percent & Number & Percent \\
\hline Fail & 3 & $0.4 \%$ & 4 & $0.2 \%$ & 1 & $0.1 \%$ \\
Pass & 396 & $48.4 \%$ & 973 & $49.9 \%$ & 526 & $50.7 \%$ \\
Good & 291 & $35.5 \%$ & 675 & $34.6 \%$ & 378 & $36.5 \%$ \\
Excellent & 129 & $15.8 \%$ & 297 & $15.2 \%$ & 132 & $12.7 \%$ \\
\hline Total & 819 & $100.0 \%$ & 1,949 & $100.0 \%$ & 1,037 & $100.0 \%$ \\
\hline
\end{tabular}

Middle 3

Middle 2

Middle 1

Middle high

\begin{tabular}{lcccccccc}
\hline & Number & Percent & Number & Percent & Number & Percent & Number & Percent \\
\hline Fail & - & - & 5 & $0.3 \%$ & 1 & $0.1 \%$ & - & - \\
Pass & 473 & $56.1 \%$ & 906 & $54.9 \%$ & 802 & $51.1 \%$ & 16 & $55.2 \%$ \\
Good & 253 & $30.0 \%$ & 487 & $29.5 \%$ & 502 & $32.0 \%$ & 10 & $34.5 \%$ \\
Excellent & 117 & $13.9 \%$ & 251 & $15.2 \%$ & 263 & $16.8 \%$ & 3 & $10.3 \%$ \\
\hline Total & 843 & $100.0 \%$ & 1,649 & $100.0 \%$ & 1,568 & $100.0 \%$ & 29 & $100.0 \%$ \\
\hline
\end{tabular}

${ }^{19}$ Primary school interns do not have annual evaluations. 
Table 3. Wage regression (log of wage, CNY/month)

\begin{tabular}{lrrrr}
\hline & \multicolumn{2}{c}{ Primary School } & \multicolumn{2}{c}{ Middle School } \\
& coef & se & coef & se \\
\hline Primary 2 & $0.690^{* * *}$ & 0.050 & & \\
Primary 1 & $1.043^{* * *}$ & 0.059 & & \\
Primary high & $1.155^{* * *}$ & 0.072 & & \\
Middle 2 & & & $0.084^{* * *}$ & 0.026 \\
Middle 1 & & & $0.149 * * *$ & 0.031 \\
Middle high & & & $0.281^{* * *}$ & 0.049 \\
Experience & $-0.018^{* * *}$ & 0.007 & $0.033^{* * *}$ & 0.004 \\
Experience squared & $0.001^{* * *}$ & 0.000 & $-0.001^{* * *}$ & 0.000 \\
Evaluation score 2006 & -0.013 & 0.015 & -0.009 & 0.008 \\
Education - middle school & -0.061 & 0.140 & $($ dropped) & \\
Education - high school & -0.088 & 0.114 & $-0.130^{*}$ & 0.069 \\
Education - vocational middle school & 0.135 & 0.116 & $-0.055^{*}$ & 0.029 \\
Education - vocational college & -0.021 & 0.158 & 0.010 & 0.170 \\
Education - four year degree & $0.335^{* * *}$ & 0.120 & -0.035 & 0.029 \\
Education - graduate school & $0.705^{* * *}$ & 0.156 & 0.002 & 0.037 \\
Constant & $6.071^{* * *}$ & 0.138 & $6.851^{* * *}$ & 0.043 \\
\hline Number of observations & 1,330 & \multicolumn{3}{c}{943} \\
Adjusted R2 & 0.560 & & 0.432 & \\
\hline note: & & & &
\end{tabular}

note: ${ }^{* *} \mathrm{p}<0.01,{ }^{* *} \mathrm{p}<0.05, * \mathrm{p}<0.1$

Table 4. Salaries across ranks (CNY / month)

\begin{tabular}{lccc}
\hline & Average salary & Standard deviation & Increase \\
\hline Primary 2 & 974.15 & 261.23 & - \\
Primary 1 & 1289.63 & 230.19 & $32.4 \%$ \\
Primary high & 1511.27 & 271.48 & $17.2 \%$ \\
Middle 3 & 1015.87 & 235.4 & - \\
Middle 2 & 1270.69 & 229.79 & $25.1 \%$ \\
Middle 1 & 1534.88 & 233.46 & $20.8 \%$ \\
Middle high & 1865.62 & 263.54 & $21.5 \%$ \\
\hline
\end{tabular}


Table 5. No competition or ability variables, Primary 2 - Middle 1

\begin{tabular}{|c|c|c|c|c|c|c|c|c|c|c|c|c|}
\hline & \multicolumn{2}{|c|}{ Primary 2} & \multicolumn{2}{|c|}{ Primary 1} & \multicolumn{2}{|c|}{ Primary high } & \multicolumn{2}{|c|}{ Middle 3} & \multicolumn{2}{|c|}{ Middle 2} & \multicolumn{2}{|c|}{ Middle 1} \\
\hline & coef & se & coef & se & coef & se & coef & se & coef & se & coef & se \\
\hline 2 years after & 0.068 & 0.086 & -0.072 & 0.074 & -0.043 & 0.085 & 0.161 & 0.108 & 0.056 & 0.064 & -0.068 & 0.083 \\
\hline 3 years after & 0.055 & 0.101 & -0.030 & 0.085 & -0.112 & 0.094 & -0.131 & 0.140 & 0.117 & 0.074 & -0.100 & 0.093 \\
\hline 4 years after & -0.116 & 0.139 & -0.084 & 0.094 & $-0.198^{*}$ & 0.103 & -0.222 & 0.221 & 0.125 & 0.087 & -0.019 & 0.106 \\
\hline 5 years after & 0.232 & 0.235 & 0.124 & 0.102 & $-0.300 * * *$ & 0.112 & $-0.675^{* *}$ & 0.316 & $0.219 * *$ & 0.108 & $-0.227^{*}$ & 0.122 \\
\hline 6 years after & -0.219 & 0.373 & -0.053 & 0.113 & $-0.285^{* *}$ & 0.123 & -0.453 & 0.440 & $0.307 * *$ & 0.121 & $-0.414^{* * *}$ & 0.140 \\
\hline 7 years after & -0.543 & 0.462 & -0.047 & 0.121 & $-0.428 * * *$ & 0.146 & & & $0.329 * *$ & 0.134 & -0.244 & 0.164 \\
\hline \multicolumn{13}{|l|}{8 years after (for } \\
\hline $\begin{array}{l}\text { Primary } 2,8 \text { to } 13 \\
\text { yrs) }\end{array}$ & -0.439 & 0.486 & -0.005 & 0.128 & $-0.569 * * *$ & 0.156 & & & $0.268^{*}$ & 0.154 & $-0.373 * *$ & 0.179 \\
\hline $\begin{array}{l}9 \text { years after (for } \\
\text { Primary 2, } 14 \text { yrs) }\end{array}$ & (dropped) & & -0.010 & 0.135 & $-0.722 * * *$ & 0.168 & & & 0.193 & 0.164 & -0.300 & 0.202 \\
\hline 10 years after & & & -0.006 & 0.147 & $-0.696 * * *$ & 0.176 & & & 0.241 & 0.177 & -0.230 & 0.223 \\
\hline 11 years after & & & 0.040 & 0.163 & $-0.887 * * *$ & 0.184 & & & 0.297 & 0.196 & -0.164 & 0.261 \\
\hline 12 years after & & & -0.094 & 0.193 & $-0.959 * * *$ & 0.199 & & & 0.204 & 0.215 & -0.190 & 0.280 \\
\hline 13 years after & & & 0.054 & 0.210 & $-1.002 * * *$ & 0.212 & & & 0.191 & 0.244 & -0.346 & 0.302 \\
\hline 14 years after & & & 0.008 & 0.266 & $-1.353 * * *$ & 0.337 & & & 0.281 & 0.277 & -0.132 & 0.367 \\
\hline 15 years after & & & 0.172 & 0.304 & $-1.308^{* * *}$ & 0.421 & & & 0.292 & 0.368 & & \\
\hline 16 years after & & & -0.037 & 0.312 & & & & & & & & \\
\hline 17 years after & & & -0.199 & 0.319 & & & & & & & & \\
\hline 18 years after & & & -0.235 & 0.343 & & & & & & & & \\
\hline 19 years after & & & -0.142 & 0.416 & & & & & & & & \\
\hline Constant & $2.728 * * *$ & 0.072 & $2.646 * * *$ & 0.092 & $3.011^{* * *}$ & 0.100 & $2.646 * * *$ & 0.081 & $2.404^{* * *}$ & 0.077 & $2.706 * * *$ & 0.092 \\
\hline $\begin{array}{l}\text { Number of } \\
\text { observations }\end{array}$ & 472 & & 1,691 & & 1,006 & & 257 & & 1,259 & & 687 & \\
\hline Adjusted R2 & 0.029 & & 0.017 & & 0.047 & & 0.081 & & 0.012 & & 0.033 & \\
\hline
\end{tabular}


Table 6. Ability variables included, Primary 2 - Middle 1

\begin{tabular}{|c|c|c|c|c|c|c|c|c|c|c|c|c|}
\hline & \multicolumn{2}{|c|}{ Primary 2} & \multicolumn{2}{|c|}{ Primary 1} & \multicolumn{2}{|c|}{ Primary high } & \multicolumn{2}{|c|}{ Middle 3} & \multicolumn{2}{|c|}{ Middle 2} & \multicolumn{2}{|c|}{ Middle 1} \\
\hline & coef & se & coef & se & coef & se & coef & se & coef & se & coef & se \\
\hline 2 years after & 0.330 & 0.247 & 0.036 & 0.131 & -0.091 & 0.166 & 0.135 & 0.391 & 0.109 & 0.103 & 0.023 & 0.105 \\
\hline 3 years after & 0.265 & 0.254 & -0.013 & 0.141 & -0.104 & 0.176 & -0.276 & 0.388 & $0.236 * *$ & 0.113 & -0.077 & 0.125 \\
\hline 4 years after & 0.017 & 0.288 & 0.012 & 0.154 & -0.199 & 0.196 & -0.666 & 0.483 & $0.325^{* *}$ & 0.126 & 0.085 & 0.146 \\
\hline 5 years after & 0.410 & 0.375 & 0.204 & 0.160 & -0.191 & 0.204 & -0.911 & 0.586 & $0.431 * * *$ & 0.155 & -0.157 & 0.170 \\
\hline 6 years after & 0.364 & 0.635 & 0.163 & 0.175 & -0.183 & 0.218 & -0.940 & 1.047 & $0.464 * * *$ & 0.176 & -0.292 & 0.195 \\
\hline 7 years after & 0.234 & 0.846 & 0.215 & 0.186 & -0.256 & 0.252 & & & $0.447 * *$ & 0.196 & 0.076 & 0.231 \\
\hline $\begin{array}{l}8 \text { years after (for } \\
\text { Primary } 2,8 \text { to } 13 \text { yrs) }\end{array}$ & 0.260 & 0.894 & $0.335^{*}$ & 0.195 & -0.272 & 0.276 & & & $0.498 * *$ & 0.232 & -0.173 & 0.256 \\
\hline $\begin{array}{l}9 \text { years after (for } \\
\text { Primary 2, } 14 \text { yrs) }\end{array}$ & (dropped) & & $0.344^{*}$ & 0.205 & -0.235 & 0.304 & & & $0.478 *$ & 0.252 & 0.064 & 0.292 \\
\hline 10 years after & & & $0.445 * *$ & 0.219 & -0.292 & 0.315 & & & $0.583^{* *}$ & 0.269 & -0.100 & 0.322 \\
\hline 11 years after & & & $0.569 * *$ & 0.239 & -0.325 & 0.328 & & & 0.474 & 0.302 & -0.065 & 0.387 \\
\hline 12 years after & & & 0.431 & 0.276 & -0.365 & 0.346 & & & 0.404 & 0.334 & -0.115 & 0.420 \\
\hline 13 years after & & & $0.515^{*}$ & 0.294 & -0.371 & 0.356 & & & 0.266 & 0.368 & -0.229 & 0.445 \\
\hline 14 years after & & & 0.240 & 0.369 & -0.544 & 0.502 & & & 0.264 & 0.412 & 0.044 & 0.525 \\
\hline 15 years after & & & 0.369 & 0.510 & -0.460 & 0.613 & & & 0.118 & 0.540 & & \\
\hline 16 years after & & & 0.305 & 0.540 & & & & & & & & \\
\hline 17 years after & & & 0.167 & 0.547 & & & & & & & & \\
\hline 18 years after & & & 0.017 & 0.569 & & & & & & & & \\
\hline 19 years after & & & -0.146 & 0.637 & & & & & & & & \\
\hline $\begin{array}{l}\text { Score of all teachers } \\
\text { but you }\end{array}$ & -0.017 & 0.033 & -0.022 & 0.057 & -0.036 & 0.066 & 0.008 & 0.044 & 0.032 & 0.049 & $0.197^{*}$ & 0.104 \\
\hline $\begin{array}{l}\text { Timing of tests } \\
\text { (relative to peers) }\end{array}$ & 0.039 & 0.146 & 0.022 & 0.184 & -0.567 & 0.422 & 0.118 & 0.163 & $0.187^{*}$ & 0.111 & 0.023 & 0.081 \\
\hline Ability index quintile 1 & -0.000 & 0.006 & 0.005 & 0.005 & 0.003 & 0.006 & -0.003 & 0.002 & -0.006 & 0.004 & -0.009 & 0.008 \\
\hline Ability index quintile 2 & -0.127 & 0.240 & 0.197 & 0.180 & 0.280 & 0.313 & -0.041 & 0.264 & 0.103 & 0.181 & -0.002 & 0.286 \\
\hline Ability index quintile 4 & $0.573 * *$ & 0.265 & $0.454 * * *$ & 0.137 & 0.157 & 0.227 & 0.448 & 0.419 & 0.076 & 0.111 & -0.189 & 0.153 \\
\hline Ability index quintile 5 & -0.005 & 0.007 & 0.003 & 0.005 & -0.008 & 0.008 & 0.001 & 0.003 & 0.001 & 0.006 & 0.000 & 0.002 \\
\hline
\end{tabular}




\begin{tabular}{|c|c|c|c|c|c|c|c|c|c|c|c|c|}
\hline Constant & $2.498 * * *$ & 0.166 & $2.450 * * *$ & 0.223 & $2.906 * * *$ & 0.289 & $2.649 * * *$ & 0.276 & $2.188^{* * *}$ & 0.172 & $2.078 * * *$ & 0.335 \\
\hline $\begin{array}{l}\text { Number of } \\
\text { observations }\end{array}$ & 312 & & 1,221 & & 658 & & 170 & & 936 & & 525 & \\
\hline Adjusted R2 & 0.082 & & 0.042 & & 0.020 & & 0.159 & & 0.034 & & 0.089 & \\
\hline
\end{tabular}

note: ${ }^{* * *} p<0.01, * * p<0.05, * p<0.1$ 


\section{Appendix}

Table A1. Proportion of teachers in the sample promoted after $x$ years

\begin{tabular}{|c|c|c|c|c|c|}
\hline & $\begin{array}{c}\text { Primary } 2 \text { to } \\
\text { Primary } 1\end{array}$ & $\begin{array}{l}\text { Primary } 1 \text { to } \\
\text { Primary high }\end{array}$ & $\begin{array}{c}\text { Middle } 3 \text { to } \\
\text { Middle } 2\end{array}$ & $\begin{array}{c}\text { Middle } 2 \text { to } \\
\text { Middle } 1\end{array}$ & $\begin{array}{l}\text { Middle } 1 \text { to } \\
\text { Middle high }\end{array}$ \\
\hline 1 year & 2.08 & - & 5.05 & 1.15 & - \\
\hline 2 years & 7.62 & 3.85 & 21.3 & 1.72 & 11.11 \\
\hline 3 years & 15.47 & 4.33 & 28.88 & 4.6 & - \\
\hline 4 years & 27.02 & 4.81 & 19.13 & 10.92 & - \\
\hline 5 years & 24.71 & 11.54 & 14.08 & 20.69 & - \\
\hline 6 years & 5.54 & 11.54 & 6.5 & 10.92 & - \\
\hline 7 years & 4.62 & 9.62 & 1.81 & 9.2 & - \\
\hline 8 years & 2.31 & 10.58 & 1.44 & 12.07 & - \\
\hline 9 years & 3 & 6.25 & 1.81 & 10.34 & 33.33 \\
\hline 10 years & 1.85 & 10.1 & - & 6.32 & 11.11 \\
\hline 11 years & 0.92 & 9.62 & - & 2.3 & 11.11 \\
\hline 12 years & 1.15 & 6.25 & - & 4.02 & - \\
\hline 13 years & 1.15 & 3.37 & - & 4.02 & 11.11 \\
\hline 14 years & 0.69 & 1.44 & - & 1.15 & 11.11 \\
\hline 15 years & 0.69 & 1.92 & - & - & 11.11 \\
\hline 16 years & 0.23 & 2.88 & - & - & - \\
\hline 17 years & 0.23 & 1.92 & - & - & - \\
\hline 18 years & 0.23 & - & - & - & - \\
\hline 19 years & - & - & - & - & - \\
\hline 20 years & - & - & - & - & - \\
\hline 21 years & 0.23 & - & - & - & - \\
\hline 22 years & - & - & - & - & - \\
\hline 23 years & - & - & - & - & - \\
\hline 24 years & 0.23 & - & - & - & - \\
\hline 25 years & - & - & - & - & - \\
\hline 26 years & - & - & - & 0.57 & - \\
\hline $\begin{array}{l}\text { Longest } \\
\text { without } \\
\text { promotion } \\
\text { to next } \\
\text { level }\end{array}$ & 20 years & 29 years & 20 years & $\begin{array}{c}52 \text { years } \\
\text { (followed by } \\
20 \text { ) }\end{array}$ & 22 years \\
\hline
\end{tabular}


Table A2. School Fixed-Effects regression on evaluation scores, Primary 2

\begin{tabular}{|c|c|c|c|c|c|c|c|c|c|c|c|c|}
\hline & \multicolumn{2}{|c|}{$\begin{array}{l}\text { No competition } \\
\text { variables }\end{array}$} & \multicolumn{2}{|c|}{$\begin{array}{l}\text { Last year's } \\
\text { evaluation }\end{array}$} & \multicolumn{2}{|c|}{$\begin{array}{l}\text { Evaluations of all } \\
\text { teachers but you }\end{array}$} & \multicolumn{2}{|c|}{ Ability variables } & \multicolumn{2}{|c|}{$\begin{array}{l}\text { All competition and } \\
\text { ability var's }\end{array}$} & \multicolumn{2}{|c|}{$\begin{array}{l}\text { Ability index } \\
\text { quintiles }\end{array}$} \\
\hline & coef & se & coef & se & coef & se & coef & se & coef & se & coef & se \\
\hline 2 years after promotion & 0.068 & 0.086 & $0.189 *$ & 0.104 & 0.253 & 0.232 & 0.192 & 0.161 & 0.202 & 0.285 & 0.330 & 0.247 \\
\hline 3 years after promotion & 0.055 & 0.101 & 0.161 & 0.134 & 0.192 & 0.251 & 0.222 & 0.180 & 0.155 & 0.304 & 0.265 & 0.254 \\
\hline 4 years after promotion & -0.116 & 0.139 & 0.084 & 0.183 & -0.022 & 0.297 & 0.055 & 0.224 & -0.059 & 0.353 & 0.017 & 0.288 \\
\hline 5 years after promotion & 0.232 & 0.235 & 0.346 & 0.283 & 0.382 & 0.372 & 0.423 & 0.343 & 0.370 & 0.430 & 0.410 & 0.375 \\
\hline 6 years after promotion & -0.219 & 0.373 & 0.271 & 0.555 & 0.249 & 0.628 & 0.422 & 0.913 & 0.325 & 0.963 & 0.364 & 0.635 \\
\hline 7 years after promotion & -0.543 & 0.462 & 0.026 & 0.699 & 0.187 & 0.823 & 0.263 & 1.075 & 0.019 & 1.118 & 0.234 & 0.846 \\
\hline $\begin{array}{l}8 \text { to } 13 \text { years after } \\
\text { promotion }\end{array}$ & -0.439 & 0.486 & 0.092 & 0.724 & 0.196 & 0.870 & 0.281 & 1.116 & -0.005 & 1.161 & 0.260 & 0.894 \\
\hline $\begin{array}{l}14 \text { years after } \\
\text { promotion }\end{array}$ & (dropped) & & (dropped) & & (dropped) & & (dropped) & & (dropped) & & (dropped) & \\
\hline $\begin{array}{l}\text { Excellent evaluation } \\
\text { last year }\end{array}$ & & & $-0.480 * * *$ & 0.162 & & & & & $-0.521 * *$ & 0.206 & & \\
\hline $\begin{array}{l}\text { Good evaluation last } \\
\text { year }\end{array}$ & & & 0.002 & 0.110 & & & & & -0.115 & 0.144 & & \\
\hline $\begin{array}{l}\text { Proportion of teachers } \\
\text { in same rank }\end{array}$ & & & -0.003 & 0.521 & -0.499 & 0.665 & & & -0.608 & 0.742 & & \\
\hline $\begin{array}{l}\text { Score of all teachers } \\
\text { but you }\end{array}$ & & & & & -0.014 & 0.031 & & & -0.009 & 0.037 & -0.017 & 0.033 \\
\hline $\begin{array}{l}\text { Education test (relative } \\
\text { to peers) }\end{array}$ & & & & & & & -0.002 & 0.008 & 0.031 & 0.045 & & \\
\hline $\begin{array}{l}\text { Psychology test } \\
\text { (relative to peers) }\end{array}$ & & & & & & & -0.002 & 0.012 & -0.007 & 0.013 & & \\
\hline $\begin{array}{l}\text { Language test (relative } \\
\text { to peers) }\end{array}$ & & & & & & & -0.000 & 0.010 & -0.007 & 0.012 & & \\
\hline $\begin{array}{l}\text { Education level } \\
\text { (relative to peers) }\end{array}$ & & & & & & & 0.161 & 1.457 & 0.666 & 1.570 & & \\
\hline $\begin{array}{l}\text { Timing of test (relative } \\
\text { to peers) }\end{array}$ & & & & & & & 0.024 & 0.159 & 0.023 & 0.176 & 0.039 & 0.146 \\
\hline Ability quintile 1 & & & & & & & & & & & -0.000 & 0.006 \\
\hline Ability quintile 2 & & & & & & & & & & & -0.127 & 0.240 \\
\hline
\end{tabular}


R2

0.029

0.089

0.045

0.036

0.108

note: ${ }^{* * *} \mathrm{p}<0.01,{ }^{* *} \mathrm{p}<0.05,{ }^{*} \mathrm{p}<0.1$

Table A3. School Fixed-Effects regression on evaluation scores, Primary 1

\begin{tabular}{|c|c|c|c|c|c|c|c|c|c|c|c|c|}
\hline & \multicolumn{2}{|c|}{$\begin{array}{l}\text { No competition } \\
\text { variables }\end{array}$} & \multicolumn{2}{|c|}{$\begin{array}{l}\text { Last year's } \\
\text { evaluation }\end{array}$} & \multicolumn{2}{|c|}{$\begin{array}{l}\text { Evaluations of all } \\
\text { teachers but you }\end{array}$} & \multicolumn{2}{|c|}{ Ability variables } & \multicolumn{2}{|c|}{$\begin{array}{l}\text { All competition and } \\
\text { ability var's }\end{array}$} & \multicolumn{2}{|c|}{$\begin{array}{l}\text { Ability index } \\
\text { quintiles }\end{array}$} \\
\hline & coef & se & coef & se & coef & se & coef & se & coef & se & coef & se \\
\hline 2 years after promotion & -0.072 & 0.074 & -0.047 & 0.084 & -0.015 & 0.092 & 0.010 & 0.129 & -0.055 & 0.143 & 0.036 & 0.131 \\
\hline 3 years after promotion & -0.030 & 0.085 & -0.090 & 0.105 & -0.055 & 0.115 & -0.013 & 0.139 & -0.085 & 0.154 & -0.013 & 0.141 \\
\hline 4 years after promotion & -0.084 & 0.094 & -0.048 & 0.125 & -0.036 & 0.135 & 0.015 & 0.153 & -0.055 & 0.167 & 0.012 & 0.154 \\
\hline 5 years after promotion & 0.124 & 0.102 & 0.129 & 0.138 & 0.163 & 0.148 & 0.229 & 0.161 & 0.156 & 0.176 & 0.204 & 0.160 \\
\hline 6 years after promotion & -0.053 & 0.113 & 0.146 & 0.156 & 0.116 & 0.166 & 0.252 & 0.180 & 0.156 & 0.194 & 0.163 & 0.175 \\
\hline 7 years after promotion & -0.047 & 0.121 & 0.104 & 0.170 & 0.177 & 0.181 & $0.335^{*}$ & 0.192 & 0.276 & 0.206 & 0.215 & 0.186 \\
\hline 8 years after promotion & -0.005 & 0.128 & 0.230 & 0.182 & 0.304 & 0.192 & $0.519 * *$ & 0.206 & $0.444 * *$ & 0.219 & $0.335^{*}$ & 0.195 \\
\hline 9 years after promotion & -0.010 & 0.135 & 0.258 & 0.191 & 0.307 & 0.202 & $0.613^{* * *}$ & 0.217 & $0.549 * *$ & 0.229 & $0.344 *$ & 0.205 \\
\hline 10 years after promotion & -0.006 & 0.147 & 0.316 & 0.205 & $0.422^{*}$ & 0.217 & $0.670 * * *$ & 0.233 & $0.658 * * *$ & 0.244 & $0.445^{* *}$ & 0.219 \\
\hline 11 years after promotion & 0.040 & 0.163 & $0.437^{*}$ & 0.225 & $0.527^{* *}$ & 0.238 & $0.828 * * *$ & 0.258 & $0.814^{* * *}$ & 0.270 & $0.569 * *$ & 0.239 \\
\hline 12 years after promotion & -0.094 & 0.193 & 0.276 & 0.263 & 0.388 & 0.275 & $0.758 * *$ & 0.304 & $0.718^{* *}$ & 0.316 & 0.431 & 0.276 \\
\hline 13 years after promotion & 0.054 & 0.210 & 0.391 & 0.281 & $0.493^{*}$ & 0.293 & $0.867 * * *$ & 0.324 & $0.869 * * *$ & 0.333 & $0.515^{*}$ & 0.294 \\
\hline 14 years after promotion & 0.008 & 0.266 & 0.302 & 0.347 & 0.254 & 0.369 & $0.924^{* *}$ & 0.440 & $1.009 * *$ & 0.446 & 0.240 & 0.369 \\
\hline 15 years after promotion & 0.172 & 0.304 & 0.377 & 0.463 & 0.340 & 0.511 & $0.928^{*}$ & 0.530 & $1.020^{*}$ & 0.563 & 0.369 & 0.510 \\
\hline 16 years after promotion & -0.037 & 0.312 & 0.328 & 0.486 & 0.266 & 0.542 & 0.809 & 0.562 & 0.943 & 0.606 & 0.305 & 0.540 \\
\hline 17 years after promotion & -0.199 & 0.319 & 0.141 & 0.496 & 0.133 & 0.549 & 0.608 & 0.578 & 0.660 & 0.618 & 0.167 & 0.547 \\
\hline 18 years after promotion & -0.235 & 0.343 & 0.005 & 0.518 & -0.019 & 0.570 & 0.381 & 0.604 & 0.451 & 0.643 & 0.017 & 0.569 \\
\hline
\end{tabular}




\begin{tabular}{|c|c|c|c|c|c|c|c|c|c|c|c|c|}
\hline 19 years after promotion & -0.142 & 0.416 & -0.167 & 0.590 & -0.191 & 0.638 & 0.438 & 0.681 & 0.463 & 0.715 & -0.146 & 0.637 \\
\hline $\begin{array}{l}\text { Excellent evaluation last } \\
\text { year }\end{array}$ & & & $-0.334 * * *$ & 0.067 & & & & & $-0.285 * * *$ & 0.083 & & \\
\hline Good evaluation last year & & & -0.014 & 0.048 & & & & & -0.060 & 0.058 & & \\
\hline $\begin{array}{l}\text { Proportion of teachers in } \\
\text { same rank }\end{array}$ & & & 0.040 & 0.324 & 0.034 & 0.353 & & & 0.157 & 0.400 & & \\
\hline $\begin{array}{l}\text { Score of all teachers but } \\
\text { you }\end{array}$ & & & & & -0.019 & 0.056 & & & -0.020 & 0.065 & -0.022 & 0.057 \\
\hline $\begin{array}{l}\text { Education test (relative } \\
\text { to peers) }\end{array}$ & & & & & & & 0.000 & 0.001 & -0.000 & 0.001 & & \\
\hline $\begin{array}{l}\text { Psychology test (relative } \\
\text { to peers) }\end{array}$ & & & & & & & -0.001 & 0.003 & -0.001 & 0.003 & & \\
\hline $\begin{array}{l}\text { Language test (relative to } \\
\text { peers) }\end{array}$ & & & & & & & 0.000 & 0.000 & 0.000 & 0.000 & & \\
\hline $\begin{array}{l}\text { Education level (relative } \\
\text { to peers) }\end{array}$ & & & & & & & -1.653 & 1.367 & -1.810 & 1.586 & & \\
\hline $\begin{array}{l}\text { Timing of test (relative to } \\
\text { peers) }\end{array}$ & & & & & & & 0.026 & 0.197 & -0.082 & 0.211 & 0.022 & 0.184 \\
\hline Ability quintile 1 & & & & & & & & & & & 0.005 & 0.005 \\
\hline Ability quintile 2 & & & & & & & & & & & 0.197 & 0.180 \\
\hline Ability quintile 4 & & & & & & & & & & & $0.454 * * *$ & 0.137 \\
\hline Ability quintile 5 & & & & & & & & & & & 0.003 & 0.005 \\
\hline Constant & $2.646^{* * *}$ & 0.092 & $2.509 * * *$ & 0.191 & $2.481^{* * *}$ & 0.264 & $2.285^{* * *}$ & 0.139 & $2.375^{* * *}$ & 0.294 & $2.450 * * *$ & 0.223 \\
\hline Number of observations & 1,691 & & 1,299 & & 1,221 & & 1,035 & & 967 & & 1,221 & \\
\hline $\mathrm{R} 2$ & 0.017 & & 0.052 & & 0.024 & & 0.037 & & 0.061 & & 0.042 & \\
\hline
\end{tabular}

note: ${ }^{* * *} \mathrm{p}<0.01,{ }^{* *} \mathrm{p}<0.05,{ }^{*} \mathrm{p}<0.1$ 
Table A4. School Fixed-Effects regression on evaluation scores, Primary high

\begin{tabular}{|c|c|c|c|c|c|c|c|c|c|c|c|c|}
\hline & \multicolumn{2}{|c|}{$\begin{array}{l}\text { No competition } \\
\text { variables }\end{array}$} & \multicolumn{2}{|c|}{$\begin{array}{l}\text { Last year's } \\
\text { evaluation }\end{array}$} & \multicolumn{2}{|c|}{$\begin{array}{l}\text { Evaluations of all } \\
\text { teachers but you }\end{array}$} & \multicolumn{2}{|c|}{ Ability variables } & \multicolumn{2}{|c|}{$\begin{array}{l}\text { All competition and } \\
\text { ability var's }\end{array}$} & \multicolumn{2}{|c|}{$\begin{array}{l}\text { Ability index } \\
\text { quintiles }\end{array}$} \\
\hline & coef & se & coef & se & coef & se & coef & se & coef & se & coef & se \\
\hline 2 years after promotion & -0.043 & 0.085 & -0.031 & 0.097 & 0.054 & 0.112 & $-0.404 * *$ & 0.164 & $-0.566 * *$ & 0.229 & -0.091 & 0.166 \\
\hline 3 years after promotion & -0.112 & 0.094 & -0.035 & 0.116 & 0.024 & 0.132 & $-0.479 * * *$ & 0.185 & $-0.658 * * *$ & 0.247 & -0.104 & 0.176 \\
\hline 4 years after promotion & $-0.198^{*}$ & 0.103 & -0.113 & 0.138 & -0.076 & 0.160 & $-0.561 * * *$ & 0.202 & $-0.763 * * *$ & 0.270 & -0.199 & 0.196 \\
\hline 5 years after promotion & $-0.300 * * *$ & 0.112 & -0.199 & 0.150 & -0.085 & 0.174 & $-0.426^{* *}$ & 0.208 & $-0.476^{*}$ & 0.279 & -0.191 & 0.204 \\
\hline 6 years after promotion & $-0.285^{* *}$ & 0.123 & -0.193 & 0.166 & -0.077 & 0.191 & $-0.494 * *$ & 0.221 & $-0.621^{* *}$ & 0.296 & -0.183 & 0.218 \\
\hline 7 years after promotion & $-0.428 * * *$ & 0.146 & -0.259 & 0.198 & -0.144 & 0.229 & $-0.482^{*}$ & 0.258 & $-0.587^{*}$ & 0.344 & -0.256 & 0.252 \\
\hline 8 years after promotion & $-0.569 * * *$ & 0.156 & -0.318 & 0.217 & -0.162 & 0.257 & $-0.591 * *$ & 0.281 & $-0.684^{*}$ & 0.380 & -0.272 & 0.276 \\
\hline 9 years after promotion & $-0.722 * * *$ & 0.168 & -0.347 & 0.242 & -0.142 & 0.286 & $-0.633^{* *}$ & 0.311 & $-0.712^{*}$ & 0.426 & -0.235 & 0.304 \\
\hline 10 years after promotion & $-0.696 * * *$ & 0.176 & -0.412 & 0.258 & -0.211 & 0.300 & $-0.576^{*}$ & 0.326 & -0.721 & 0.454 & -0.292 & 0.315 \\
\hline 11 years after promotion & $-0.887 * * *$ & 0.184 & $-0.503^{*}$ & 0.271 & -0.251 & 0.319 & $-0.770 * *$ & 0.344 & $-0.903 *$ & 0.476 & -0.325 & 0.328 \\
\hline 12 years after promotion & $-0.959 * * *$ & 0.199 & $-0.562^{*}$ & 0.290 & -0.307 & 0.340 & $-0.926 * *$ & 0.360 & $-1.076^{* *}$ & 0.498 & -0.365 & 0.346 \\
\hline 13 years after promotion & $-1.002^{* * *}$ & 0.212 & $-0.541^{*}$ & 0.301 & -0.318 & 0.349 & $-0.809 * *$ & 0.369 & $-0.973^{*}$ & 0.508 & -0.371 & 0.356 \\
\hline 14 years after promotion & $-1.353^{* * *}$ & 0.337 & $-0.843^{* *}$ & 0.428 & -0.485 & 0.498 & $-1.130 * *$ & 0.552 & $-1.285^{*}$ & 0.665 & -0.544 & 0.502 \\
\hline 15 years after promotion & $-1.308^{* * *}$ & 0.421 & -0.767 & 0.572 & -0.414 & 0.612 & -1.110 & 0.806 & -1.250 & 0.900 & -0.460 & 0.613 \\
\hline $\begin{array}{l}\text { Excellent evaluation last } \\
\text { year }\end{array}$ & & & $-0.178^{* *}$ & 0.077 & & & & & -0.022 & 0.118 & & \\
\hline Good evaluation last year & & & -0.031 & 0.056 & & & & & 0.035 & 0.081 & & \\
\hline $\begin{array}{l}\text { Proportion of teachers in } \\
\text { same rank }\end{array}$ & & & -0.350 & 0.525 & -0.143 & 0.585 & & & 0.646 & 0.842 & & \\
\hline $\begin{array}{l}\text { Score of all teachers but } \\
\text { you }\end{array}$ & & & & & -0.025 & 0.065 & & & -0.042 & 0.095 & -0.036 & 0.066 \\
\hline $\begin{array}{l}\text { Education test (relative to } \\
\text { peers) }\end{array}$ & & & & & & & 0.001 & 0.004 & 0.002 & 0.004 & & \\
\hline $\begin{array}{l}\text { Psychology test (relative } \\
\text { to peers) }\end{array}$ & & & & & & & -0.001 & 0.001 & -0.001 & 0.001 & & \\
\hline $\begin{array}{l}\text { Language test (relative to } \\
\text { peers) }\end{array}$ & & & & & & & -0.000 & 0.000 & 0.002 & 0.005 & & \\
\hline Education level (relative to & & & & & & & -0.527 & 2.247 & -0.830 & 2.483 & & \\
\hline
\end{tabular}


peers)

Timing of test (relative to

peers)

$\begin{array}{lllll}-0.986 * * & 0.496 & -1.392 * * & 0.636 & -0.567\end{array}$

0.422

Ability quintile 1

Ability quintile 2

Ability quintile 4

Ability quintile 5

\begin{tabular}{|c|c|c|c|c|c|c|c|c|c|c|c|c|}
\hline $\begin{array}{l}\text { limıng of test (relative to } \\
\text { peers) }\end{array}$ & & & & & & & $-0.986 * *$ & 0.496 & $-1.392 * *$ & 0.636 & -0.567 & 0.422 \\
\hline Ability quintile 1 & & & & & & & & & & & 0.003 & 0.006 \\
\hline Ability quintile 2 & & & & & & & & & & & 0.280 & 0.313 \\
\hline Ability quintile 4 & & & & & & & & & & & 0.157 & 0.227 \\
\hline Ability quintile 5 & & & & & & & & & & & -0.008 & 0.008 \\
\hline Constant & $3.011^{* * *}$ & 0.100 & $2.945^{* * *}$ & 0.206 & $2.801 * * *$ & 0.330 & $3.080 * * *$ & 0.192 & $3.139 * * *$ & 0.473 & $2.906 * * *$ & 0.289 \\
\hline Number of observations & 1,006 & & 792 & & 658 & & 478 & & 396 & & 658 & \\
\hline $\mathrm{R} 2$ & 0.047 & & 0.023 & & 0.008 & & 0.051 & & 0.077 & & 0.020 & \\
\hline
\end{tabular}

note: $* * * p<0.01, * * p<0.05, * p<0.1$

Table A5. School Fixed-Effects regression on evaluation scores, Middle 3

\begin{tabular}{|c|c|c|c|c|c|c|c|c|c|c|c|c|}
\hline & \multicolumn{2}{|c|}{$\begin{array}{l}\text { No competition } \\
\text { variables }\end{array}$} & \multicolumn{2}{|c|}{$\begin{array}{l}\text { Last year's } \\
\text { evaluation }\end{array}$} & \multicolumn{2}{|c|}{$\begin{array}{l}\text { Evaluations of all } \\
\text { teachers but you }\end{array}$} & \multicolumn{2}{|c|}{ Ability variables } & \multicolumn{2}{|c|}{$\begin{array}{l}\text { All competition and } \\
\text { ability var's }\end{array}$} & \multicolumn{2}{|c|}{$\begin{array}{l}\text { Ability index } \\
\text { quintiles }\end{array}$} \\
\hline & coef & se & coef & se & coef & se & coef & se & coef & se & coef & se \\
\hline 2 years after promotion & 0.161 & 0.108 & 0.060 & 0.141 & 0.065 & 0.329 & -0.158 & 0.261 & -0.189 & 0.502 & 0.135 & 0.391 \\
\hline 3 years after promotion & -0.131 & 0.140 & -0.033 & 0.192 & -0.216 & 0.350 & -0.319 & 0.264 & -0.339 & 0.509 & -0.276 & 0.388 \\
\hline 4 years after promotion & -0.222 & 0.221 & -0.473 & 0.337 & -0.525 & 0.469 & $-0.710 *$ & 0.386 & -0.778 & 0.617 & -0.666 & 0.483 \\
\hline 5 years after promotion & $-0.675^{* *}$ & 0.316 & -0.792 & 0.489 & -0.635 & 0.613 & $-1.127 * *$ & 0.538 & -1.003 & 0.767 & -0.911 & 0.586 \\
\hline 6 years after promotion & -0.453 & 0.440 & -0.611 & 0.669 & 0.183 & 0.953 & -0.909 & 0.669 & -0.109 & 1.067 & -0.940 & 1.047 \\
\hline $\begin{array}{l}\text { Excellent evaluation last } \\
\text { year }\end{array}$ & & & $-0.352 *$ & 0.208 & & & & & -0.402 & 0.251 & & \\
\hline Good evaluation last year & & & -0.187 & 0.163 & & & & & $-0.511 *$ & 0.281 & & \\
\hline $\begin{array}{l}\text { Proportion of teachers in } \\
\text { same rank }\end{array}$ & & & 0.895 & 0.779 & 1.020 & 0.878 & & & 1.137 & 0.980 & & \\
\hline $\begin{array}{l}\text { Score of all teachers but } \\
\text { you }\end{array}$ & & & & & 0.014 & 0.036 & & & 0.029 & 0.048 & 0.008 & 0.044 \\
\hline $\begin{array}{l}\text { Education test (relative } \\
\text { to peers) }\end{array}$ & & & & & & & -0.005 & 0.007 & -0.003 & 0.007 & & \\
\hline
\end{tabular}




\begin{tabular}{|c|c|c|c|c|c|c|c|c|c|c|c|c|}
\hline $\begin{array}{l}\text { Psychology test (relative } \\
\text { to peers) }\end{array}$ & & & & & & & -0.002 & 0.005 & -0.002 & 0.006 & & \\
\hline $\begin{array}{l}\text { Language test (relative to } \\
\text { peers) }\end{array}$ & & & & & & & 0.002 & 0.002 & 0.002 & 0.002 & & \\
\hline $\begin{array}{l}\text { Education level (relative } \\
\text { to peers) }\end{array}$ & & & & & & & 3.051 & 2.727 & 1.640 & 3.032 & & \\
\hline $\begin{array}{l}\text { Timing of test (relative to } \\
\text { peers) }\end{array}$ & & & & & & & 0.002 & 0.168 & 0.113 & 0.187 & 0.118 & 0.163 \\
\hline Ability quintile 1 & & & & & & & & & & & -0.003 & 0.002 \\
\hline Ability quintile 2 & & & & & & & & & & & -0.041 & 0.264 \\
\hline Ability quintile 4 & & & & & & & & & & & 0.448 & 0.419 \\
\hline Ability quintile 5 & & & & & & & & & & & 0.001 & 0.003 \\
\hline Constant & $2.646 * * *$ & 0.081 & $2.593 * * *$ & 0.300 & $2.404 * * *$ & 0.386 & $2.857 * * *$ & 0.174 & $2.737^{* * *}$ & 0.480 & $2.649 * * *$ & 0.276 \\
\hline Number of observations & 257 & & 194 & & 174 & & 170 & & 158 & & 170 & \\
\hline $\mathrm{R} 2$ & 0.081 & & 0.132 & & 0.132 & & 0.126 & & 0.222 & & 0.159 & \\
\hline
\end{tabular}
note: ${ }^{* * *} p<0.01, * * p<0.05, * p<0.1$

Table A6. School Fixed-Effects regression on evaluation scores, Middle 2

\begin{tabular}{|c|c|c|c|c|c|c|c|c|c|c|c|c|}
\hline & \multicolumn{2}{|c|}{$\begin{array}{l}\text { No competition } \\
\text { variables }\end{array}$} & \multicolumn{2}{|c|}{ Last year's evaluation } & \multicolumn{2}{|c|}{$\begin{array}{l}\text { Evaluations of all } \\
\text { teachers but you }\end{array}$} & \multicolumn{2}{|c|}{ Ability variables } & \multicolumn{2}{|c|}{$\begin{array}{l}\text { All competition and } \\
\text { ability var's }\end{array}$} & \multicolumn{2}{|c|}{$\begin{array}{l}\text { Ability index } \\
\text { quintiles }\end{array}$} \\
\hline & coef & se & coef & se & coef & se & coef & se & coef & se & coef & se \\
\hline 2 years after promotion & 0.056 & 0.064 & 0.022 & 0.072 & 0.010 & 0.078 & $0.171^{*}$ & 0.102 & 0.151 & 0.110 & 0.109 & 0.103 \\
\hline 3 years after promotion & 0.117 & 0.074 & 0.133 & 0.090 & 0.145 & 0.097 & $0.284 * *$ & 0.111 & $0.263^{* *}$ & 0.120 & $0.236^{* *}$ & 0.113 \\
\hline 4 years after promotion & 0.125 & 0.087 & $0.241^{* *}$ & 0.112 & $0.257^{* *}$ & 0.118 & $0.343^{* * *}$ & 0.124 & $0.314^{* *}$ & 0.132 & $0.325^{* *}$ & 0.126 \\
\hline 5 years after promotion & $0.219 * *$ & 0.108 & $0.365^{* *}$ & 0.143 & $0.380 * *$ & 0.150 & $0.403 * * *$ & 0.151 & $0.345^{* *}$ & 0.158 & $0.431 * * *$ & 0.155 \\
\hline 6 years after promotion & $0.307^{* *}$ & 0.121 & $0.448 * * *$ & 0.164 & $0.432^{* *}$ & 0.173 & $0.380 * *$ & 0.174 & $0.348^{*}$ & 0.180 & $0.464 * * *$ & 0.176 \\
\hline 7 years after promotion & $0.329 * *$ & 0.134 & $0.434^{* *}$ & 0.184 & $0.447^{* *}$ & 0.193 & $0.346 *$ & 0.191 & 0.323 & 0.197 & $0.447 * *$ & 0.196 \\
\hline 8 years after promotion & $0.268^{*}$ & 0.154 & $0.411^{*}$ & 0.216 & $0.521^{* *}$ & 0.230 & 0.341 & 0.225 & $0.408^{*}$ & 0.233 & $0.498^{* *}$ & 0.232 \\
\hline 9 years after promotion & 0.193 & 0.164 & 0.370 & 0.235 & $0.512^{* *}$ & 0.250 & 0.220 & 0.244 & 0.287 & 0.254 & $0.478^{*}$ & 0.252 \\
\hline 10 years after promotion & 0.241 & 0.177 & 0.411 & 0.252 & $0.635^{* *}$ & 0.267 & 0.194 & 0.265 & 0.292 & 0.276 & $0.583^{* *}$ & 0.269 \\
\hline
\end{tabular}




\begin{tabular}{|c|c|c|c|c|c|c|c|c|c|c|c|c|}
\hline 11 years after promotion & 0.297 & 0.196 & 0.415 & 0.277 & $0.595^{* *}$ & 0.294 & 0.256 & 0.292 & 0.354 & 0.303 & 0.474 & 0.302 \\
\hline 12 years after promotion & 0.204 & 0.215 & 0.367 & 0.305 & 0.525 & 0.324 & 0.020 & 0.319 & 0.165 & 0.331 & 0.404 & 0.334 \\
\hline 13 years after promotion & 0.191 & 0.244 & 0.271 & 0.339 & 0.387 & 0.360 & -0.188 & 0.357 & -0.067 & 0.371 & 0.266 & 0.368 \\
\hline 14 years after promotion & 0.281 & 0.277 & 0.304 & 0.372 & 0.417 & 0.402 & -0.066 & 0.392 & -0.065 & 0.415 & 0.264 & 0.412 \\
\hline 15 years after promotion & 0.292 & 0.368 & 0.246 & 0.453 & 0.237 & 0.537 & -0.281 & 0.487 & -0.262 & 0.534 & 0.118 & 0.540 \\
\hline $\begin{array}{l}\text { Excellent evaluation last } \\
\text { year }\end{array}$ & & & $-0.295 * * *$ & 0.081 & & & & & $-0.315 * * *$ & 0.088 & & \\
\hline Good evaluation last year & & & -0.065 & 0.057 & & & & & -0.083 & 0.063 & & \\
\hline $\begin{array}{l}\text { Proportion of teachers in } \\
\text { same rank }\end{array}$ & & & 0.145 & 0.541 & -0.050 & 0.568 & & & -0.362 & 0.609 & & \\
\hline $\begin{array}{l}\text { Score of all teachers but } \\
\text { you }\end{array}$ & & & & & 0.033 & 0.048 & & & 0.078 & 0.056 & 0.032 & 0.049 \\
\hline $\begin{array}{l}\text { Education test (relative } \\
\text { to peers) }\end{array}$ & & & & & & & -0.003 & 0.005 & -0.009 & 0.006 & & \\
\hline $\begin{array}{l}\text { Psychology test (relative } \\
\text { to peers) }\end{array}$ & & & & & & & $0.002 *$ & 0.001 & $0.002 *$ & 0.001 & & \\
\hline $\begin{array}{l}\text { Language test (relative to } \\
\text { peers) }\end{array}$ & & & & & & & 0.000 & 0.001 & 0.000 & 0.001 & & \\
\hline $\begin{array}{l}\text { Education level (relative } \\
\text { to peers) }\end{array}$ & & & & & & & $-2.168 * *$ & 1.056 & $-1.867^{*}$ & 1.134 & & \\
\hline $\begin{array}{l}\text { Timing of test (relative to } \\
\text { peers) }\end{array}$ & & & & & & & 0.180 & 0.122 & 0.185 & 0.132 & $0.187^{*}$ & 0.111 \\
\hline Ability quintile 1 & & & & & & & & & & & -0.006 & 0.004 \\
\hline Ability quintile 2 & & & & & & & & & & & 0.103 & 0.181 \\
\hline Ability quintile 4 & & & & & & & & & & & 0.076 & 0.111 \\
\hline Ability quintile 5 & & & & & & & & & & & 0.001 & 0.006 \\
\hline Constant & $2.404 * * *$ & 0.077 & $2.330 * * *$ & 0.231 & $2.230 * * *$ & 0.282 & $2.354 * * *$ & 0.112 & $2.357^{* * *}$ & 0.302 & $2.188 * * *$ & 0.172 \\
\hline Number of observations & 1,259 & & 1,000 & & 936 & & 890 & & 841 & & 936 & \\
\hline $\mathrm{R} 2$ & 0.012 & & 0.042 & & 0.023 & & 0.048 & & 0.075 & & 0.034 & \\
\hline
\end{tabular}

note: ${ }^{* * *} \mathrm{p}<0.01,{ }^{* *} \mathrm{p}<0.05,{ }^{*} \mathrm{p}<0.1$ 
Table A7. School Fixed-Effects regression on evaluation scores, Middle 1

\begin{tabular}{|c|c|c|c|c|c|c|c|c|c|c|c|c|}
\hline & \multicolumn{2}{|c|}{$\begin{array}{l}\text { No competition } \\
\text { variables }\end{array}$} & \multicolumn{2}{|c|}{$\begin{array}{l}\text { Last year's } \\
\text { evaluation }\end{array}$} & \multicolumn{2}{|c|}{$\begin{array}{l}\text { Evaluations of all } \\
\text { teachers but you }\end{array}$} & \multicolumn{2}{|c|}{ Ability variables } & \multicolumn{2}{|c|}{$\begin{array}{l}\text { All competition and } \\
\text { ability var's }\end{array}$} & \multicolumn{2}{|c|}{$\begin{array}{l}\text { Ability index } \\
\text { quintiles }\end{array}$} \\
\hline & coef & se & coef & se & coef & se & coef & se & coef & se & coef & se \\
\hline 2 years after promotion & -0.068 & 0.083 & 0.002 & 0.101 & -0.022 & 0.102 & 0.181 & 0.124 & 0.099 & 0.158 & 0.023 & 0.105 \\
\hline 3 years after promotion & -0.100 & 0.093 & -0.029 & 0.130 & -0.151 & 0.133 & 0.179 & 0.139 & 0.018 & 0.186 & -0.077 & 0.125 \\
\hline 4 years after promotion & -0.019 & 0.106 & 0.095 & 0.168 & -0.016 & 0.170 & 0.208 & 0.160 & 0.089 & 0.217 & 0.085 & 0.146 \\
\hline 5 years after promotion & $-0.227^{*}$ & 0.122 & -0.183 & 0.204 & -0.288 & 0.209 & 0.064 & 0.183 & -0.008 & 0.275 & -0.157 & 0.170 \\
\hline 6 years after promotion & $-0.414 * * *$ & 0.140 & -0.357 & 0.239 & $-0.453^{*}$ & 0.243 & 0.011 & 0.222 & -0.038 & 0.322 & -0.292 & 0.195 \\
\hline 7 years after promotion & -0.244 & 0.164 & -0.019 & 0.282 & -0.098 & 0.284 & 0.397 & 0.269 & 0.403 & 0.375 & 0.076 & 0.231 \\
\hline 8 years after promotion & $-0.373^{* *}$ & 0.179 & -0.261 & 0.316 & -0.387 & 0.318 & 0.111 & 0.306 & 0.116 & 0.419 & -0.173 & 0.256 \\
\hline 9 years after promotion & -0.300 & 0.202 & -0.174 & 0.354 & -0.205 & 0.357 & 0.058 & 0.336 & 0.243 & 0.459 & 0.064 & 0.292 \\
\hline 10 years after promotion & -0.230 & 0.223 & -0.238 & 0.398 & -0.404 & 0.407 & 0.195 & 0.367 & 0.198 & 0.512 & -0.100 & 0.322 \\
\hline 11 years after promotion & -0.164 & 0.261 & -0.147 & 0.480 & -0.397 & 0.488 & 0.175 & 0.443 & 0.199 & 0.594 & -0.065 & 0.387 \\
\hline 12 years after promotion & -0.190 & 0.280 & -0.218 & 0.514 & -0.452 & 0.520 & 0.165 & 0.484 & 0.241 & 0.635 & -0.115 & 0.420 \\
\hline 13 years after promotion & -0.346 & 0.302 & -0.336 & 0.563 & -0.620 & 0.570 & 0.040 & 0.507 & 0.080 & 0.687 & -0.229 & 0.445 \\
\hline 14 years after promotion & -0.132 & 0.367 & -0.111 & 0.637 & -0.366 & 0.655 & -0.023 & 0.600 & 0.124 & 0.814 & 0.044 & 0.525 \\
\hline $\begin{array}{l}\text { Excellent evaluation last } \\
\text { year }\end{array}$ & & & -0.133 & 0.099 & & & & & -0.090 & 0.118 & & \\
\hline Good evaluation last year & & & -0.022 & 0.076 & & & & & -0.064 & 0.088 & & \\
\hline $\begin{array}{l}\text { Proportion of teachers in } \\
\text { same rank }\end{array}$ & & & 0.091 & 0.702 & 0.559 & 0.716 & & & -0.035 & 0.889 & & \\
\hline $\begin{array}{l}\text { Score of all teachers but } \\
\text { you }\end{array}$ & & & & & $0.197^{*}$ & 0.103 & & & 0.191 & 0.140 & $0.197 *$ & 0.104 \\
\hline $\begin{array}{l}\text { Education test (relative } \\
\text { to peers) }\end{array}$ & & & & & & & -0.000 & 0.009 & -0.002 & 0.009 & & \\
\hline $\begin{array}{l}\text { Psychology test (relative } \\
\text { to peers) }\end{array}$ & & & & & & & $0.010^{* * *}$ & 0.004 & $0.010^{* * *}$ & 0.004 & & \\
\hline $\begin{array}{l}\text { Language test (relative to } \\
\text { peers) }\end{array}$ & & & & & & & -0.007 & 0.004 & $-0.007 *$ & 0.004 & & \\
\hline $\begin{array}{l}\text { Education level (relative } \\
\text { to peers) }\end{array}$ & & & & & & & -2.039 & 1.411 & -0.716 & 1.554 & & \\
\hline Timing of test (relative to & & & & & & & 0.204 & 0.138 & 0.155 & 0.148 & 0.023 & 0.081 \\
\hline
\end{tabular}


peers)

Ability quintile 1

Ability quintile 2

Ability quintile 4

$-0.002$

Ability quintile 5

$-0.189$

0.153

Constant

$2.706 * * *$

$0.0922 .620 * * *$

$0.1622 .042 * * *$

$0.348 \quad 2.433 * * * \quad 0.138$

0.000

0.002

Number of observations 687

555

525

397

525

R2 0.033

$0.062 \quad 0.081$

0.102

0.089

note: $* * * p<0.01, * * p<0.05, * p<0.1$ 
Table A8. Regression of proportion of teachers variable, pooled sample

\begin{tabular}{|c|c|c|}
\hline & \multicolumn{2}{|c|}{ Dummies interacted with teachers } \\
\hline & coef & se \\
\hline Primary $2 *$ teachers $* 2$ years after promotion & 0.280 & 0.282 \\
\hline Primary $2 *$ teachers $* 3$ years after promotion & 0.221 & 0.349 \\
\hline Primary $2 *$ teachers $* 4$ years after promotion & 0.127 & 0.480 \\
\hline Primary $2 *$ teachers $* 5$ years after promotion & -1.602 & 1.072 \\
\hline Primary $2 *$ teachers $* 6$ years after promotion & 0.070 & 1.668 \\
\hline Primary $2 *$ teachers $* 7$ years after promotion & -0.386 & 0.849 \\
\hline Primary $2 *$ teachers $* 8$ to 13 years after promotion & -0.510 & 0.760 \\
\hline Primary $2 *$ teachers $* 14$ years after promotion & 0.686 & 0.697 \\
\hline Primary $1 *$ teachers $* 2$ years after promotion & $-0.387^{* *}$ & 0.168 \\
\hline Primary $1 *$ teachers $* 3$ years after promotion & $-0.467 * * *$ & 0.167 \\
\hline Primary $1 *$ teachers $* 4$ years after promotion & $-0.535^{* * *}$ & 0.182 \\
\hline Primary $1 *$ teachers $* 5$ years after promotion & -0.047 & 0.174 \\
\hline Primary $1 *$ teachers $* 6$ years after promotion & $-0.311 *$ & 0.181 \\
\hline Primary $1 *$ teachers $* 7$ years after promotion & -0.132 & 0.170 \\
\hline Primary $1 *$ teachers $* 8$ years after promotion & 0.140 & 0.168 \\
\hline Primary $1 *$ teachers $* 9$ years after promotion & $0.275^{*}$ & 0.163 \\
\hline Primary $1 *$ teachers $* 10$ years after promotion & 0.227 & 0.215 \\
\hline Primary $1 *$ teachers $* 11$ years after promotion & 0.263 & 0.217 \\
\hline Primary $1 *$ teachers $* 12$ years after promotion & -0.005 & 0.279 \\
\hline Primary $1 *$ teachers $* 13$ years after promotion & 0.274 & 0.315 \\
\hline Primary $1 *$ teachers $* 14$ years after promotion & $1.172 * *$ & 0.597 \\
\hline Primary $1 *$ teachers $* 15$ years after promotion & $0.843^{*}$ & 0.489 \\
\hline Primary $1 *$ teachers $* 16$ years after promotion & -0.349 & 0.383 \\
\hline Primary $1 *$ teachers $* 17$ years after promotion & -0.158 & 0.381 \\
\hline Primary $1 *$ teachers $* 18$ years after promotion & -0.508 & 0.404 \\
\hline Primary $1 *$ teachers $* 19$ years after promotion & 0.501 & 0.549 \\
\hline Primary high * teachers $* 2$ years after promotion & -0.055 & 0.319 \\
\hline Primary high * teachers $* 3$ years after promotion & -0.245 & 0.322 \\
\hline Primary high $*$ teachers $* 4$ years after promotion & -0.303 & 0.295 \\
\hline Primary high $*$ teachers $* 5$ years after promotion & 0.052 & 0.306 \\
\hline Primary high * teachers $* 6$ years after promotion & -0.094 & 0.339 \\
\hline Primary high * teachers $* 7$ years after promotion & -0.071 & 0.462 \\
\hline Primary high * teachers $* 8$ years after promotion & -0.516 & 0.518 \\
\hline Primary high $*$ teachers $* 9$ years after promotion & -0.452 & 0.529 \\
\hline Primary high * teachers $* 10$ years after promotion & -0.057 & 0.517 \\
\hline Primary high * teachers $* 11$ years after promotion & -0.379 & 0.366 \\
\hline Primary high * teachers $* 12$ years after promotion & $-0.957 * *$ & 0.408 \\
\hline Primary high * teachers $* 13$ years after promotion & $-0.779 *$ & 0.426 \\
\hline Primary high * teachers $* 14$ years after promotion & -1.296 & 1.252 \\
\hline Primary high * teachers $* 15$ years after promotion & -0.610 & 0.775 \\
\hline
\end{tabular}




\begin{tabular}{|c|c|c|}
\hline Middle $3 *$ teachers $* 2$ years after promotion & $0.643 * *$ & 0.309 \\
\hline Middle $3 *$ teachers $* 3$ years after promotion & -0.358 & 0.511 \\
\hline Middle $3 *$ teachers $* 4$ years after promotion & 1.178 & 0.756 \\
\hline Middle $3 *$ teachers $* 5$ years after promotion & -0.712 & 1.179 \\
\hline Middle $3 *$ teachers $* 6$ years after promotion & 0.389 & 2.006 \\
\hline Middle $2 *$ teachers $* 2$ years after promotion & -0.017 & 0.162 \\
\hline Middle $2 *$ teachers $* 3$ years after promotion & -0.038 & 0.168 \\
\hline Middle $2 *$ teachers $* 4$ years after promotion & 0.090 & 0.182 \\
\hline Middle $2 *$ teachers $* 5$ years after promotion & -0.003 & 0.214 \\
\hline Middle $2 *$ teachers $* 6$ years after promotion & 0.143 & 0.223 \\
\hline Middle $2 *$ teachers $* 7$ years after promotion & 0.099 & 0.217 \\
\hline Middle $2 *$ teachers $* 8$ years after promotion & 0.099 & 0.248 \\
\hline Middle $2 *$ teachers $* 9$ years after promotion & -0.009 & 0.246 \\
\hline Middle $2 *$ teachers $* 10$ years after promotion & -0.146 & 0.248 \\
\hline Middle $2 *$ teachers $* 11$ years after promotion & -0.219 & 0.276 \\
\hline Middle $2 *$ teachers $* 12$ years after promotion & -0.298 & 0.269 \\
\hline Middle $2 *$ teachers $* 13$ years after promotion & -0.418 & 0.335 \\
\hline Middle $2 *$ teachers $* 14$ years after promotion & -0.406 & 0.459 \\
\hline Middle $2 *$ teachers $* 15$ years after promotion & $-1.292^{*}$ & 0.709 \\
\hline Middle $1 *$ teachers $* 2$ years after promotion & -0.144 & 0.279 \\
\hline Middle $1 *$ teachers $* 3$ years after promotion & -0.072 & 0.319 \\
\hline Middle $1 *$ teachers $* 4$ years after promotion & 0.310 & 0.329 \\
\hline Middle $1 *$ teachers $* 5$ years after promotion & -0.426 & 0.337 \\
\hline Middle $1 *$ teachers $* 6$ years after promotion & -0.344 & 0.410 \\
\hline Middle $1 *$ teachers $* 7$ years after promotion & 0.111 & 0.563 \\
\hline Middle $1 *$ teachers $* 8$ years after promotion & 0.587 & 0.555 \\
\hline Middle $1 *$ teachers $* 9$ years after promotion & $1.334^{* *}$ & 0.557 \\
\hline Middle $1 *$ teachers $* 10$ years after promotion & $1.743^{* * *}$ & 0.570 \\
\hline Middle $1 *$ teachers $* 11$ years after promotion & 0.907 & 0.733 \\
\hline Middle $1 *$ teachers $* 12$ years after promotion & 0.960 & 0.847 \\
\hline Middle $1 *$ teachers $* 13$ years after promotion & -0.532 & 0.773 \\
\hline Middle $1 *$ teachers $* 14$ years after promotion & -0.011 & 1.140 \\
\hline Middle high $*$ teachers $* 2$ years after promotion & 15.294 & 44.837 \\
\hline Middle high $*$ teachers $* 3$ years after promotion & 15.294 & 44.837 \\
\hline Middle high $*$ teachers $* 4$ years after promotion & 15.294 & 44.837 \\
\hline Education test (relative to others) & 0.001 & 0.000 \\
\hline Psychology test (relative to others) & 0.000 & 0.001 \\
\hline Language test (relative to others) & 0.000 & 0.000 \\
\hline Years of education (relative to others) & -0.209 & 0.140 \\
\hline Timing of tests (relative to others) & $0.044^{*}$ & 0.025 \\
\hline Constant & $2.607^{* * *}$ & 0.020 \\
\hline Number of observations & 3,864 & \\
\hline $\mathrm{R} 2$ & 0.031 & \\
\hline
\end{tabular}


